\title{
Two-Dimensional Nanomaterials-Based Polymer Composites: Fabrication and Energy Storage Applications
}

\author{
Wei Liu, ${ }^{1}$ Bakhtar Ullah, ${ }^{1}$ Ching-Ching Kuo, ${ }^{2}$ and Xingke Cai $\mathbb{D}^{1}$ \\ ${ }^{1}$ Institute for Advanced Study, Shenzhen University, Shenzhen, Guangdong 518060, China \\ ${ }^{2}$ Institute of Organic and Polymeric Materials, National Taipei University of Technology, Taipei 106, Taiwan \\ Correspondence should be addressed to Xingke Cai; cai.xingke@szu.edu.cn
}

Received 10 July 2019; Revised 7 September 2019; Accepted 17 October 2019; Published 20 December 2019

Guest Editor: Yong Ren Copyright $\odot 2019$ Wei Liu et al. This is an open access article distributed under the Creative Commons Attribution License, which
permits unrestricted use, distribution, and reproduction in any medium, provided the original work is properly cited.

\begin{abstract}
Polymers have been widely used for their low density, low cost, corrosion resistance, easy design, and processing. The addition of nanomaterials into polymer matrices has been studied for a long history due to their enhancement on properties of polymers, such as the electrical conductivity, thermal conductivity, corrosion resistance, and wear resistance. Two-dimensional materials, a new class of nanomaterials, have been intensively studied as a filler for polymer composites in recent years, which can significantly enhance the performance at even extremely small loading. In this review, firstly, the preparing and modifying method of $2 \mathrm{D}$ materials, such as graphene, graphene oxide, and hexagonal boron nitride, as a filler for polymer composites are organized. The related dispersion methods of 2D materials in the polymers, surface treatments of $2 \mathrm{D}$ materials, interface bonding between 2D materials and polymers are discussed alongside. Secondly, the applications of 2D materials/polymer composites for energy storage in lithium ion battery separators and supercapacitors are summarized. Finally, we have concluded the challenges in preparing $2 \mathrm{D}$ materials/polymer composites, and future perspectives for using this class of new composites have also been discussed.
\end{abstract}

\section{Introduction of Polymer Composites}

Polymer composite can be defined as the composite materials composed of more than two phases, which typically refer to polymer/polymer or filler (fiber, metal, etc.)-based polymer composite [1]. As compared to traditional materials such as ceram and clay, the polymer composites were developed later. The polymer composites have important applications in various fields such as electronics [2], food packaging industry [3], and medicinal industry [4], etc. With the rapid development of science and technology, the demands for better performance of materials are also increasing. Traditional polymer materials made of a single component cannot satisfy the increasing demands on high comprehensive performances. For example, polymers usually have a melting temperature range of 100 $250^{\circ} \mathrm{C}$, which means that most of them are not suitable for use at high temperature. Therefore, the idea for incorporating additives into the polymer matrix was proposed, which could greatly improve the performance of the polymers. For example, Wakabayashi et al. [5] reported a significant improvement in Young's modulus by adding graphite $(2.5 \mathrm{wt} \%, 1870 \mathrm{MPa})$ into the neat PP matrix (910 MPa). Based on the progress made in various application fields, this conceptual innovation by adding inorganic materials/metals into polymer matrix has attracted broad research interests.

Compared with conventional neat polymers, polymer composites exhibit enhanced properties in various fields [6-8]. A large number of studies showed high improvement in mechanical properties $[9,10]$, electrical conductivity [11-13], thermal conductivity [14], corrosion resistance [15], and wear resistance [16], by incoporating even a little amount of additives into the polymer matrix. These properties make them suitable for commercialization in diverse fields, such as thermal conduction and dissipation devices [17], resist-memory devices [18], energy storage [19], etc. Traditional fillers such as metals and minerals are in macroscale, which have been widely used in various applications. However, these additives can not remarkably improve the properties due to the limited interfacial structure between them and the matrix. To further improve the performance of the composites, reducing the size of fillers into microscale and nanoscale should be one of the main strategies because of their large surface areas and good 
contact with the polymers [20]. Roy and Komarneni firstly proposed the idea of polymer nanocomposite in 1984, which was defined as the composite materials in which at least one of the dispersed phases was within $100 \mathrm{~nm}$, including carbon nanotubes (CNTs), fullerenes, nanosized particles, etc. [21]. These materials are very suitable for mixing with polymers to form polymer nanocomposites. Actually, the earliest report on polymer nanocomposites can be dated back to the midterm of the $1800 \mathrm{~s}$ when carbon black was blended into vulcanized rubber in the application of automobile tires. In comparison, blending with other polymers or macro-scale materials into one polymer, polymer nanocomposites exhibit enhanced mechanical [22], optical [23], and electrical properties [24]. Meanwhile, as the sizes of conventional fillers reduced to nano-scale, such as nano- $\mathrm{SiO}_{2}[25]$ and nano- $\mathrm{CaCO}_{3}[26]$, they showed better dispersity into polymer compared to macro-scale particles, and much better property enhancement effect. Therefore, only a small amount of nanomaterials needs to be used for the properties, which can reduce the cost on the fillers and avoid many side effects ascribed to the high contents of fillers.

Two-dimensional (2D) materials are a new type of sheetlike nanomaterials, typically showing lateral size from hundreds of nanometers to few micrometers and their average thickness is $<5 \mathrm{~nm}$ [27]. These materials have a large surface area with a high percentage of atoms exposed to the surface, which make them have a good interaction with the matrix and even a little amount of them can greatly increase the performance of polymers. In addition, their abundant species make them suitable fillers for different application purposes [28]. It has been reported that with a small loading $(<1-5 \mathrm{wt} \%)$ of $2 \mathrm{D}$ materials, such as the layered silicates or graphene, into a polymer matrix, the mechanical properties of the resulted polymer composites improved up to $200 \%$ compared to the neat polymers [2]. So far, a variety of $2 \mathrm{D}$ materials have been prepared and used in the polymer composites, including grapheme [29], graphene oxide (GO) [30], hexagonal boron nitride (h-BN) [31], transitional metal dichalcogenides (TMDCs) [32], metal organic frameworks (MOFs) [33], etc. In this review, we will focus on the recent progress in the fabrication of $2 \mathrm{D}$ materials-based polymer composites. Their applications in energy storage aspects will also be discussed.

The typical process to prepare 2D materials-based polymer composites comprises the preparation of exfoliated 2D materials and their dispersion into the polymer matrix. For the preparation of $2 \mathrm{D}$ materials, the exfoliation process is to weaken the interaction or break the bonds between layers [34]. With the expansion of interlayer space by intercalation, the slippage happens between layers by applying a shear force. Until now, there are various methods to exfoliate layered materials including intercalation-assisted exfoliation [35, 36], liquid phase exfoliation [36], etching assisted exfoliation [37], ball milling [38], electrochemical exfoliation [39], ion exchange-assisted exfoliation [40], etc. After the exfoliation of 2D materials, the essential task is to ensure their even dispersion into the polymer matrix. The commonly used method is dissolving the polymer in solvents and then putting the $2 \mathrm{D}$ materials into the dissolved polymer solution. However, the complicated fabrication process makes the final products expensive and the organic solvents are poisonous and harmful, which are the big challenges for the scalable use of $2 \mathrm{D}$ materials based polymer composites. Further refinement of the fabrication process is necessary to cut down the price and reduce environmental pollution. Therefore, a review on the current state of this field and the most updated stratigies to solve the challenges is very neccessary for the real use of $2 \mathrm{D}$ materials based polymer composites. In the following section, we will first introduce the preparation methods of various $2 \mathrm{D}$ materials-based polymer composites. Then, properties enhancement of different types of 2D materials-based polymer composites (graphene, h-BN, $\mathrm{MoS}_{2}$, and MOF) will be summarized. Third, the applications of $2 \mathrm{D}$ materials/polymer composites for lithium ion batteries and supercapacitors will be summarized. Finally, the challenge for exfoliating and preparing polymer nanocomposites will be discussed and the future perspective on how to improve the performance of polymer composites will be concluded.

\section{Graphene-, GO-Based Polymer Composites}

The history of graphene can track back to 2004 when Novoselov et al. [41] firstly obtained the few-layered graphenes by scotch tape transferring technique and characterized their excellent electrical performance. This milestone work inspired the basic research and commercialization of graphene. The graphene is composed of carbon atoms tightly packed into $2 \mathrm{D}$ honeycomb lattice structure through $\mathrm{sp}^{2}$ hybridization. Such a structure displays versatile physical and chemical properties, such as high carrier mobility at room temperature $(\sim 10,000$ $\left.\mathrm{cm}^{2} \mathrm{~V}^{-1} \mathrm{~s}^{-1}\right)$ [41], high Young's modulus $(\sim 1 \mathrm{TPa})$ [42], large theoretical specific surface area $\left(2630 \mathrm{~m}^{2} \mathrm{~g}^{-1}\right)$ [43], low light absorption $(\sim 2.3 \%)$ [44], and high thermal conductivity $\left(\sim 5000 \mathrm{Wm}^{-1} \mathrm{~K}^{-1}\right)$ [45]. GO is an essential derivative of graphene, which was obtained by strong oxidation of the graphite with oxidative agents. During the oxidation process, various oxygen-containing functional groups such as carboxyl, hydroxyl, epoxy groups, etc., are introduced on the surface of grapheme [43]. Despite a similar 2D structure, graphene and GO have totally different properties. For example, GO has a much poorer electrical conductivity than graphene due to the transformation of $\mathrm{C}-\mathrm{C}$ bonds from $\mathrm{sp}^{2}$ to $\mathrm{sp}^{3}$ hybridization by the strong oxidation process. The graphene is insoluble in water, and GO exhibits excellent dispersity in water due to the large amount of hydrophilic oxygen-containing groups on the surface. Therefore, graphene and GO show different application purpose for polymer composites.

Before the development of graphene and GO, CNTs were commonly used as fillers for polymer composites. The high cost of preparing CNTs and their aggregation were the bottlenecks restricting their applications in polymer composites [46]. Currently, the mass production of graphene and GO has been well solved and their costs were also acceptable for commercial applications $[47,48]$. Therefore, they are considered as suitable fillers to replace CNTs for polymer composites. To optimize the properties of the polymer composites, it is essential to make the filler well dispersed in the polymer matrix and interact tightly with them. So far, various methods for the 


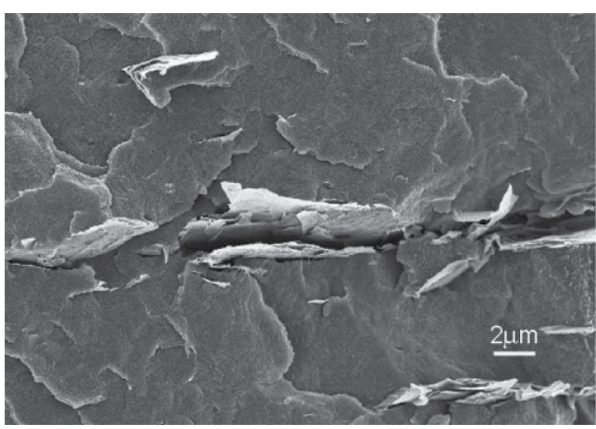

(a)

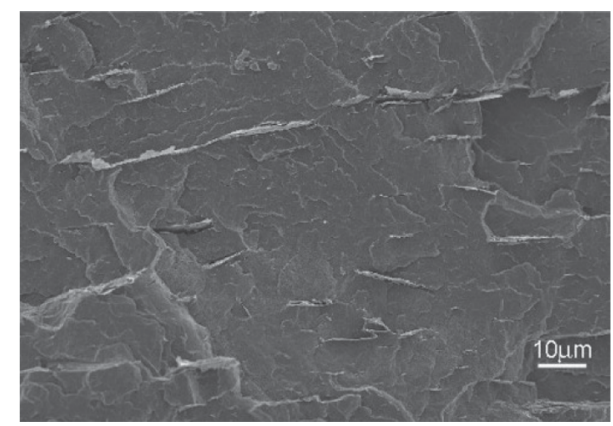

(b)

FIGURE 1: SEM images of (a) expanded graphite (EG)-PVDF and (b) functionalized graphene sheets (FGS)-PVDF showing the surface integrality. Adapted from [61].

preparation of graphene and GO-based polymer nanocomposites have been well established, including solution mixing [49-51], ball milling [38, 52], in situ polymerization [53-56], etc. In the following subsections, the mechanism and principles of these methods will be introduced in detail and enhanced properties from the experimental data will be reviewed.

\subsection{Graphene-Based Polymer Composites}

\subsubsection{Fabrication Methods of Graphene-Based Polymer} Composites. There are two main strategies to fabricate the graphene-based polymer composites: in situ polymerization and melt intercalation [9]. In situ polymerization is a popular method for preparation of graphene-based polymer nanocomposites. Generally, in situ polymerization for graphene is started with suitable monomers, such as epoxy and aniline. For a typical process, by the loading of a suitable initiator such as room temperature ionic liquids (RTILs) [57], polymerization is initiated with the strong shear force exerted on the untreated flaky graphene and epoxy. The as-exfoliated few-layered graphene nanosheets are directly dispersed into the epoxy. On the other hand, appropriate initiators need to be selected for different polymers. For example, ammonium persulfate served as a free-radical agent to initiate the oxidative polymerization of aniline [58]. Besides the applied high-shear force to the composites, heat, electrochemical polymerization, and radiation are the other useful ways to initiate the polymerization of monomers to prepare graphenebased polymer composites [59, 60]. For example, anodic electropolymerization has been used to polymerize aniline onto graphene papers by directly applying a voltage in an aniline solution with the graphene papers as an electrode. This method has been applied to prepare various graphenebased polymer nanocomposites, i.e., epoxy/graphene [53], poly(vinylidene fluoride) (PVDF)/graphene (Figure 1) [56], poly(vinyl alcohol) (PVA)/grapheme [62], etc.

In the melt intercalation method, strong shear force and high temperature are simultaneously used to blend the graphene and polymer matrix in the molten state without using organic solvents [9]. Firstly, the thermoplastic polymer melts at high temperature. Then, with the help of high shear force, graphene is intercalated by the polymer chains to form polymer nanocomposites [63]. It is worth noticing that only thermoplastic polymer could be processed using this method. It has the advantage to prepare polymer composites for those can not be in situ polymerized. Meanwhile, it is worth noticing that the molecular weight of polymer and 2D material-polymer interaction are two important factors in the melt intercalation method. For example, to ensure the good dispersion of graphene into a polymer matrix, it is necessary to reduce the molecular weight of the polymer and increase the graphene-polymer interaction. Otherwise, the high entropy in composite with high molecular weight will forbid the dispersion of the filler [64]. From previous reports, a wide range of polymer composites has been successfully prepared using this method, such as polystyrene (PS)/graphene [65] and PP/ EG $[66,67]$.

\subsubsection{Properties of the Graphene-Based Polymer}

Composites. For a polymer composite, the filler influences the electrical conductivity, thermal conductivity, mechanical properties, and even the dielectric properties. The graphene has a large surface area and good interactions with the polymer matrix, which means a very small amount of them can lead to a significant change in their performance (Table 1). Taking graphene/PVDF composite as an example, the dielectric constant reached 340 with 0.2 vol\% of graphene at $100 \mathrm{~Hz}$ and the highest dielectric constant was achieved up to 7940 with 1.2 vol\% of graphene at $100 \mathrm{~Hz}$ [56]. On the other hand, to obtain polymer composites with the same dielectric constant, the loading of conventional ceramic powder needs to be extremely high, i.e., over 50 vol\%. As another example, PET-graphene composite with 3.0 vol\% graphene loading exhibited a high electrical conductivity of $\sim 2.11 \mathrm{Sm}^{-1}$ (Figure 2) [73]. The thermal stability of the polymers can also be greatly enhanced by a small loading of graphene. Loading 0.05 wt $\%$ of FGS into PMMA shows the increase of glass transition temperature $\left(T_{\mathrm{g}}\right)$ to $30^{\circ} \mathrm{C}$. With a loading of $1 \mathrm{wt} \%, \mathrm{FGS}$ into the poly(acrylonitrile) (PAN) increased $T_{\mathrm{g}}$ to $46^{\circ} \mathrm{C}$ [76]. Compared with the conventional carbon-based fillers, such as CNTs and EG, the enhancement of $T_{\mathrm{g}}$ was much higher by adding the same amount of graphene into the polymer matrix due to their $2 \mathrm{D}$ structure and the large percentage of surface atoms to interact with the polymer matrix. 
TABLE 1: Electrical conductivity enhancement in PS polymer nanocomposites.

\begin{tabular}{lcccccc}
\hline S/N & Authors & Year & Loading content & Preparation method & Electrical conductivity (S/m) & Ref \\
\hline 1 & Nadia Grossiord et al. & 2007 & $1.5 \mathrm{wt} \%$ (SWCNT) & Solution mixing & $\approx 1$ & {$[68]$} \\
2 & Mathur et al. & 2008 & $2.0 \mathrm{vol} \%$ (MWCNT) & Solution mixing & {$[69]$} \\
3 & Guo Hua Chen et al. & 2001 & $2.8-3.0$ vol\% (EG) & In situ polymerization & 1 & {$[70]$} \\
4 & Na Liu et al. & 2008 & 4.2 vol\% (graphene) & Electrochemical polymerization & 13.8 & [71] \\
5 & Xian Yong Qi et al. & 2011 & PS & & {$[6.7 \mathrm{E}-14$} \\
\hline
\end{tabular}

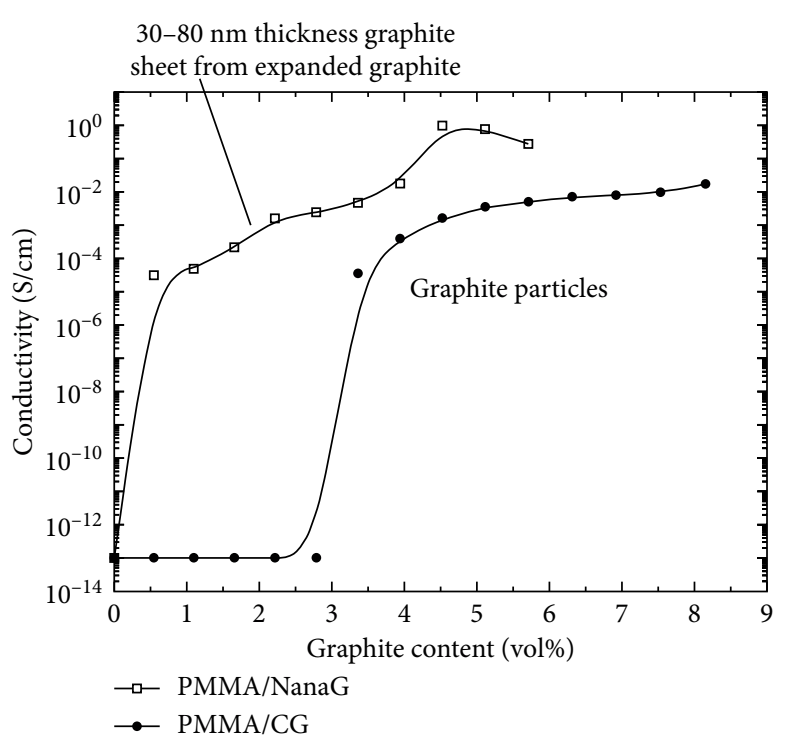

(a)

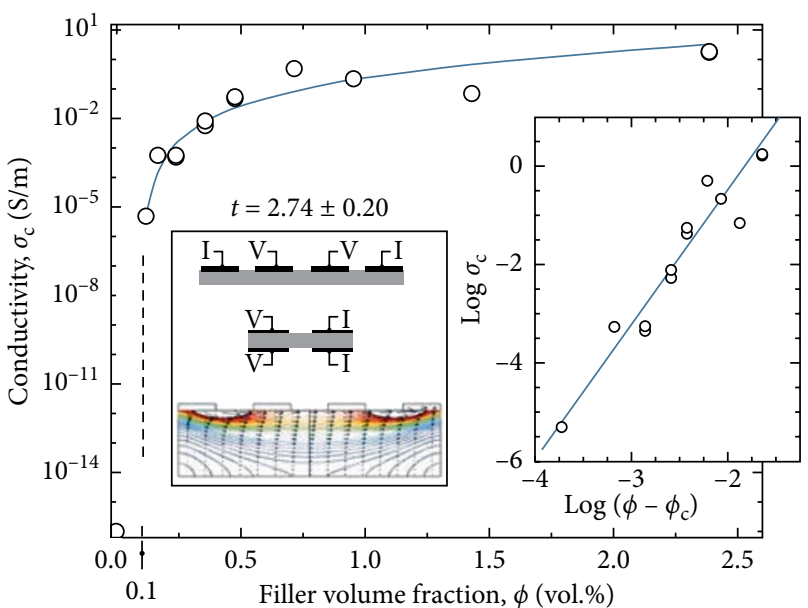

(b)

FIGURE 2: (a) Electrical conductivity of polymethyl methacrylate (PMMA)/graphite with different graphite contents. Adapted from [74]. (b) Electrical conductivity of polystyrene/graphene with different filler volume fractions. Adapted from [75].

\subsection{GO-Based Polymers}

\subsubsection{Fabrication Methods of GO-Based Polymer} Composites. The graphene-based polymer composites have very low loading limit due to the low solubility of graphene in the polymer solutions or melts. To solve these problems, the functionalized GOs, which have good stability in the solvents or melts, have been used as fillers to prepare polymer composites. For the preparation of GO-based polymer composites, solution-based mixing is one of the most convenient methods [77]. Due to the rich oxygencontaining functional groups on the surface, GOs can be easily dispersed in suitable solvents, such as dimethyl formamide (DMF) and N-methyl pyrrolidone (NMP). The polymers, such as thermoplastic polyurethane (TPU) and PVDF, can be dissolved in these organic solvents. Therefore, GO nanosheets and the polymers can be directly mixed in these solvents. By evaporating the solvents, GOs can be homogeneously dispersed in the polymer matrix. However, using costly and toxic organic solvents, this method for preparing the polymer composites is expensive, complicated, and time consuming. To avoid the scalable use of organic solvents, other methods, such as in situ exfoliations of layered materials inside a polymer matrix, have been developed.
Ball milling is one of the popular methods to exfoliate 2D materials. For a typical process, graphite oxides are used as starting materials, which are exfoliated by the shear force or great momentum provided by balls with different diameters to overcome the interlayer Van der Waals interaction of layered materials. The graphite oxides are exfoliated to GOs and then evenly dispersed in polymers [78]. The high energy generated from the collision activates the chemical activity of the polymer, helping the recombination of the atoms on the surface and modifying the surface of GO. During the process, the addition of suitable catalysts can improve the dispersion of the GO inside the matrix. For example, the oxalic acid was used for GO-phenolic resin (PF) composites to increase the interaction between the 2D materials and polymer matrix [79]. The 2D materials could be obtained in large quantities and functional groups could be grafted at the same time by such a method.

2.2.2. Properties of GO-Based Polymer Composites. GOs have rich oxidative functional groups on their surfaces, which can have good interactions with the polymer matrix [80,81]. Therefore, only a small loading can significantly improve the performance of the polymers. By using the solution mixing technique, the formed PVA/GO composite exhibited a high 
Young's modulus of $3.45 \mathrm{GPa}$ with an extremely low loading of $0.7 \mathrm{wt} \% \mathrm{GO}$, which was $62 \%$ higher than the neat PVA polymer matrix [62]. For poly(allylamine hydrochloride) (PAH) with GO nanosheets as a filler, the formed thin crosslinked film exhibited a huge increase in elastic modulus, i.e., from 3.64 to $18.31 \mathrm{GPa}$ [82]. The modulus of the GO/ epoxy resin composites reached its maximum value of $\sim 4.2$ $\mathrm{GPa}$ when the expanded GO concentration was $1.5 \mathrm{wt} \%$ [83]. Noteworthy, even for the same filler, the resulting properties can be significantly different due to the dispersity and interactions between matrices and fillers. Here, we will use the GO/epoxy resin as an example. By using the in situ polymerization method, the resultant GO/epoxy composite showed an increase of $103 \%$ in thermal conductivity as compared with the neat epoxy $\left(0.25 \mathrm{Wm}^{-1} \mathrm{~K}^{-1}\right)$, with a loading of 2 wt\% GO [84]. Similar enhancement was presented in another experiment but even with lower loading of GO [48] by using the tetraethylenepentamine (TEPA) to modify the GO sheets. The TEPA functionalized GO sheets were polymerized by a three-roll mixing method. With 0.5 $\mathrm{wt} \%$ of GO loading, this multifunctional composites of TEPA modified GO/epoxy showed an enhancement of thermal conductivity by $103 \%$ [85].

\subsection{D Graphene/Polymer Composites}

\subsubsection{Fabircation methods of $3 D$ Graphene/Polymer}

Composites. Although properties' enhancements are reported in various fields, there are several drawbacks of 2D graphene nanosheets, which restrict the development of graphene-based polymer composites. For example, the $\pi-\pi$ interaction between each graphene sheet cause the agglomeration and uneven dispersion of them, which reduce the specific surface area and active sites [86]. In addition, the graphene sheets in the matrix have poor contact with each other since they are well dispersed in the polymer solvents/melts. Therefore, organizing the $2 \mathrm{D}$ graphene sheets into a connected macroporous $3 \mathrm{D}$ structure, i.e. 3D graphene, and then fill this structure with polymers is a good method to overcome the agglomeration problems [87]. Compared with 2D materials in the composites prepared by adding them into the polymer matrix, the $2 \mathrm{D}$ materials in this preformed 3D structure showed much better contact. This good contact will improve the properties of the composites, such as electrical conductivity and thermal conductivity. Therefore, many studies have been reported about the synthesis of $3 \mathrm{D}$ graphene structures and their applications in polymers [88].

The freeze-drying process is the most straight forward way for the preparation of $3 \mathrm{D}$ graphene-based composites [89]. At extremely low temperature, the solvents in the $2 \mathrm{D}$ graphene dispersion become solids, which could be sublimated under vacuum condition. During the sublimation process, the graphene would not aggregate due to the small interfacial energy between the solids and the graphene. By using this strategy, the resulting 3D structured graphene does not stack or aggregate together, leading to a large surface area. Polymers could be filled with resulting 3D graphene-based fillers. For example, Wang et al. [90] reported the synthesis of graphene aerogel started with aqueous GO under the freeze-drying method. After constructing the 3D structure of graphene, epoxy resin was directly added and infiltrated into the as-formed aerogel under vacuum condition, forming the graphene aerogel/epoxy polymer composite.

The hydrothermal method is another convenient method to get 3D graphene filled polymers [91]. The fundamental procedure is based on the in situ polymerization. Firstly, polymers are added into the aqueous solution of GO to obtain the well-dispersed suspension. By sealing the mixture into an autoclave, the graphene will be converted to 3D graphene with the structure containing polymer. The 3D-graphene-based polymer can be obtained by using this technique and the resulting product could also be directly applied in the practical devices [92].

Chemical vapor deposition (CVD) is another method to prepare the 3D graphene with interconnected network structure. During the CVD process, the Ni foam was firstly used to grow graphene at high temperature $\left(1000^{\circ} \mathrm{C}\right)$, and then filled with polymers. After removing the solvent and etching the template, 3D graphene-polymer composites were obtained [93]. Because of the high quality of the graphene and the good interconnection in the 3D structure, the materials showed excellent electrical, thermal conductivity, and superior mechanical properties. However, the high cost of graphene preparation via CVD restricts its practical applications.

2.3.2. Properties of $3 D$ Graphene/Polymer Composites. Liu et al. prepared a 3D graphene-polypyrrole ( $\mathrm{PPy}$ ) composite by polymerization of graphene with PPy after heat conversion, which showed promising electrochemical properties. The specific capacitance measured from this composite achieved $186 \mathrm{~F} / \mathrm{g}$, which was roughly three times larger than that of the neat PPy [91]. Compared with the 3D graphene, the specific capacitance increases $33 \%$ for the $3 \mathrm{D}$ graphene-PPy. The as-fabricated supercapacitors showed very strong actuation response as an electrochemical actuator, demonstrating its ability for practical applications. As another important property parameter for polymers, the electrical conductivity of the 3D graphene/polymer composites has been widely discussed. Jia et al. found properties enhancements in various aspects, including the electrical conductivity by embedding CVD grown 3D graphene into epoxy [93]. With only 0.2 $\mathrm{wt} \%$ loading of 3D graphene, the electrical conductivity of the composite increased 55\% compared to neat epoxy [93]. The glass transition temperature has also shown a significant increase by $31^{\circ} \mathrm{C}(0.2 \mathrm{wt} \%$ of $3 \mathrm{D}$ graphene), which was ascribed to the excellent dispersity and the strong bonding interaction of the 3D graphene in the epoxy resin (Figure 3). 3D GO-based composites are the important derivative of $3 \mathrm{D}$ graphene. With the loading of $1.3 \mathrm{wt} \% 3 \mathrm{D}$ GO into epoxy, the thermal conductivity of the composite increased $148 \%$, up to $0.62 \mathrm{Wm}^{-1} \mathrm{~K}^{-1}$ [94]. The $3 \mathrm{D}$ structure and the low thermal resistance resulted in a high enhancement in thermal conductivity for the composites. These $3 \mathrm{D}$ graphenes showed a significant potential compared to the conventional CNTs and graphenes as fillers for polymers. 


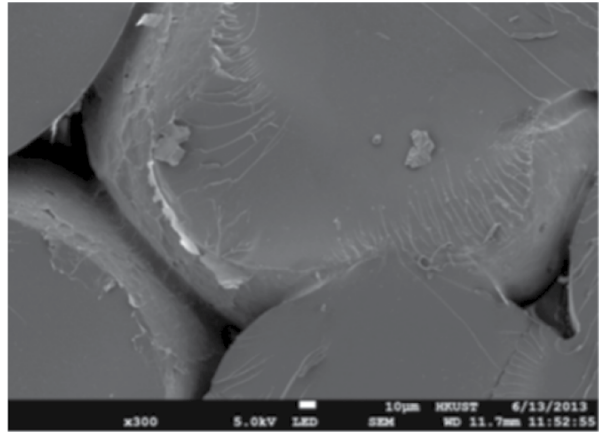

(a)

FIGURE 3: (a) SEM image of 3D graphene (0.2 wt\%)/epoxy composi $0.2 \mathrm{wt} \%$ 3D graphene. Adapted from [93].

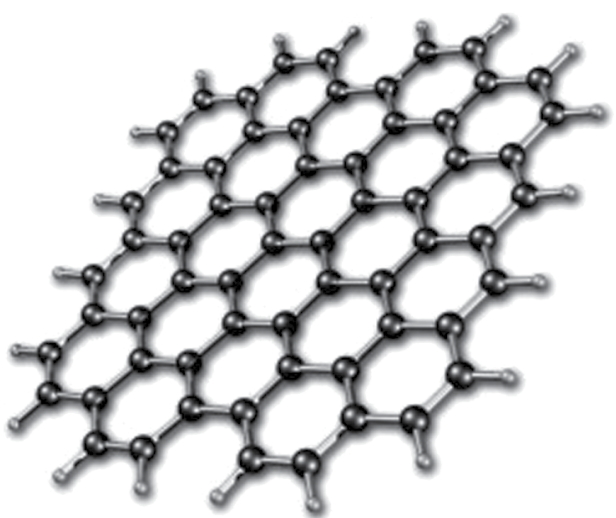

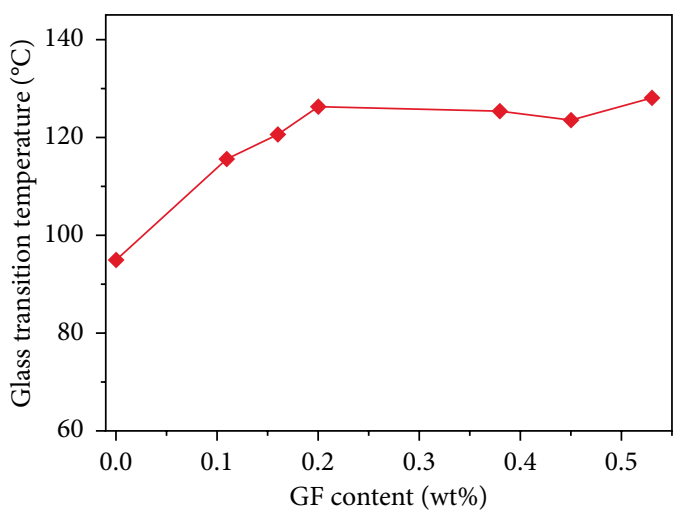

(b)

(b) Glass transition temperature reaches its threshold at the loading of

Graphene sheet

() Carbon

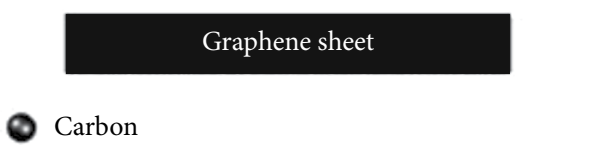

(a)

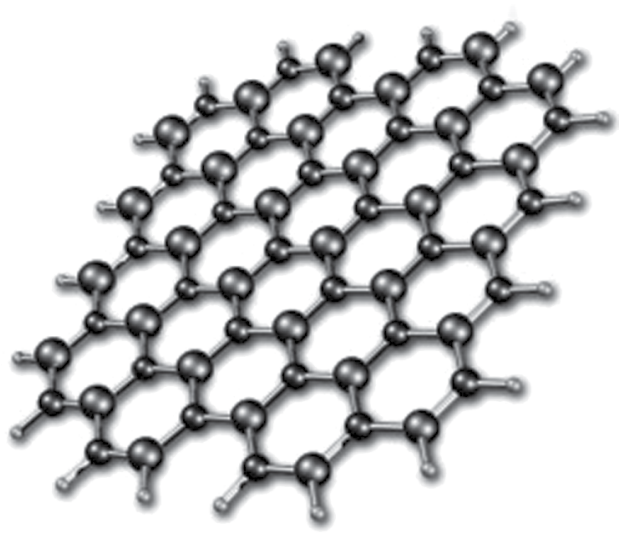

Boron nitride sheet

Boron

- Nitrogen

FIGURE 4: Schematic representation of the structure of graphene (a) and boron nitride (b). Adapted from [95].

\section{Other 2D Materials/Polymer Composites}

3.1. $h$-BN/Polymer Composites. The $2 \mathrm{D}$ h-BN has a similar structure with graphene (Figure 4), which shows high thermal conductivity, low dielectric constant and poor electrical conductivity. Therefore, it has a potential to be used in conditions where good thermal conductivity and insulating properties are needed, such as electronic devices, and thermal interface management. Their polymer composites have also been widely considered for these applications. For h-BNbased composites as a thermal interface management material, the increase of the loading will significantly improve the properties. Taking the enhancement in thermal conductivity as an example, various studies showed the potential of $\mathrm{h}-\mathrm{BN}$ as a thermal conductive filler with different types of polymer $[17,96-98]$. When the loading of h-BN is $30 \mathrm{wt} \%$, polyimide composite films achieved a thermal conductivity of
$0.47 \mathrm{Wm}^{-1} \mathrm{~K}^{-1}$ [99]. The same polymer composite has been prepared by other methods, showing thermal conductivity of 3 and $7 \mathrm{Wm}^{-1} \mathrm{~K}^{-1}$ with a loading of 30 and $60 \mathrm{vol} \%$ of h-BN [100]. Similar result for h-BN/epoxy composites was also obtained but with a slightly low loading of $33 \mathrm{vol} \%$ [101]. Despite the high thermal conductivity, the higher loading of filler does not mean good properties, good dispersity and strong interaction with the polymers are also critical for the performance of the composites. Due to the inert surface, 2D $\mathrm{h}-\mathrm{BN}$ has poor interfacial adhesion with the polymer matrix. To overcome this challenge, it is necessary to modify the surface of h-BN to improve the interfacial adhesion. Several strategies have been employed to functionalize the $2 \mathrm{D}$ h-BN, for example, PS and PMMA were used to coat h-BN particles, resulting in an enhanced interfacial adhesion [101]. Lee et al. [102] demonstrated thermal conductivity enhancement with modified h-BN/polyetherimide (PEI). Following the same idea 


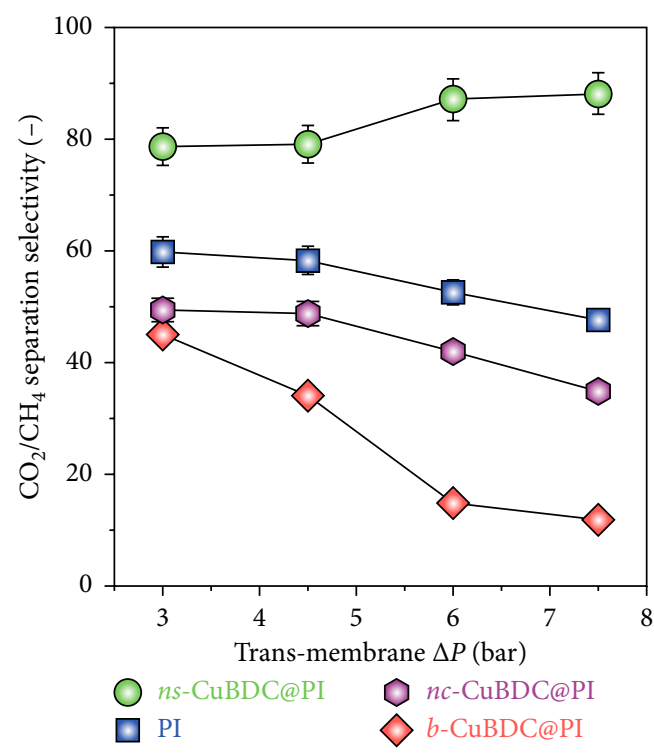

(a)

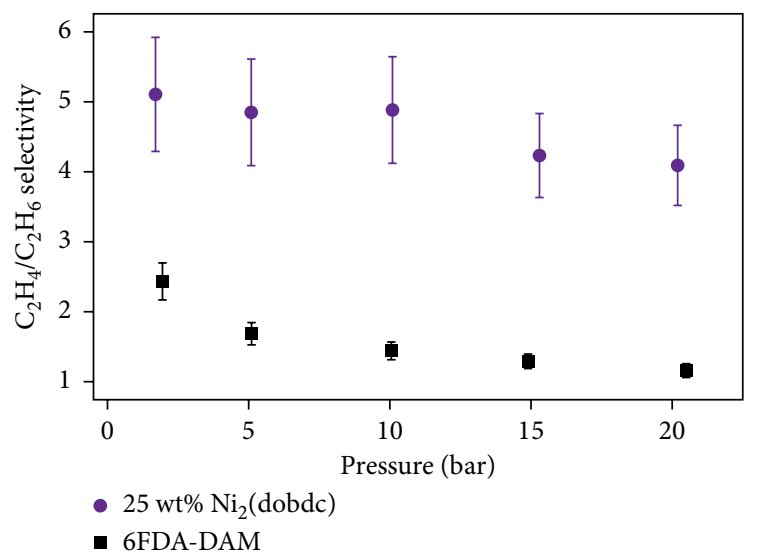

(b)

FIGURE 5: (a) Difference of separation selectivity of $\mathrm{CO}_{2} / \mathrm{CH}_{4}$ when employing several types of MOF/polymer composites. Adapted from [33]. (b) Selectivity of $\mathrm{C}_{2} \mathrm{H}_{4} / \mathrm{C}_{2} \mathrm{H}_{6}$ vs. pressure for $\mathrm{Ni}_{2}$ (dobdc) (25 wt\%)/6FDA-DAM composite. Adapted from [117].

of coating modification, $\mathrm{h}-\mathrm{BN}$ particles were pretreated by polyimide (PI). Then the PI-coated h-BN was mixed with PEI matrix to form a composite. The thermal conductivity of the composite achieved $3.3 \mathrm{~W} \mathrm{~m}^{-1} \mathrm{~K}^{-1}$ with $60 \mathrm{wt} \%$ loading, while the result was $2.6 \mathrm{~W} \mathrm{~m}^{-1} \mathrm{~K}^{-1}$ without modification. Apparently, due to the improved interfacial adhesion, the connection between polymer and $\mathrm{h}-\mathrm{BN}$ is stronger after modification of the h-BN.

3.2. $\mathrm{MoS}_{2} /$ Polymer Composites. $\mathrm{MoS}_{2}$ is another popular layered material, which is structurally analogous to graphene. It can be exfoliated into $2 \mathrm{D}$ materials using the physical or chemical methods to break the interlayered interaction, i.e., the Van der Waals force [103, 104]. As a well-known functional material, $\mathrm{MoS}_{2}$ has a good electrochemical capacitance and catalytic property, which are used for energy storage and catalysis applications $[105,106]$. Among these applications, there is a research hot spot on the lithium ion batteries (LIBs) by using $\mathrm{MoS}_{2}$ as a cathode material. To obtain a good performance of the LIBs, it is necessary to intercalate a suitable polymer into the host gallery of $\mathrm{MoS}_{2}$, making it easy for the insertion and extraction of $\mathrm{Li}^{+}$ions. Ma et al. [107] reported a large-scale preparation strategy for synthesizing $\mathrm{MoS}_{2} / \mathrm{PPy}$ composites. During the process of in situ polymerization, $\mathrm{MoS}_{2}$ was pretreated with $p$-toluenesulfonic acid and then pyrrole monomer was added. Pyrrole monomer was well dispersed in $\mathrm{MoS}_{2}$ suspension with the assistance of stirring. Later, oxidants were dropped into the mixture to get oxidative chemical composites. From the report, the specific capacitance of the $\mathrm{MoS}_{2} / \mathrm{PPy}$ composite achieved $553.7 \mathrm{~F} \mathrm{~g}^{-1}$ at the condition of $1 \mathrm{~A} \mathrm{~g}^{-1}$, which was nearly two-folds larger than the pure $\mathrm{MoS}_{2}\left(235 \mathrm{~F} \mathrm{~g}^{-1}\right)$. When the discharge current density was increased to a high value of $10 \mathrm{~A} \mathrm{~g}^{-1}$, the specific capacitance was maintained at $90 \%$ compared to the result of $1 \mathrm{~A} \mathrm{~g}^{-1}$. Xiao et al. [104] reported a significant enhancement of capacitance by using the poly(ethylene oxide) (PEO)/MoS 2 composites. The mixture of $\mathrm{Li}_{x} \mathrm{MoS}_{2}$ and PEO was dissolved in deionized water and sonicated together and then it was centrifuged to obtain the composites. From the experiment, with a loading of $5 \mathrm{wt} \% \mathrm{PEO}$, the dielectric capacity of the composite was 2 -folds of the neat $\mathrm{MoS}_{2}$, showing a similar improvement as previously reported.

3.3. MOF/Polymer Composites. MOFs are classes of porous materials with a special crystalline structure, generally composed of metal-containing nodes and constructed by organic linkers [108]. There are four typical categories of MOFs, including $0 \mathrm{D}$ for clusters, $1 \mathrm{D}$ for chains, $2 \mathrm{D}$ for layers, and 3D for frameworks [109]. 2D MOF is one type of the novel ultrathin nanosheets with a large number of cavities exposed on the surface, whose typical thickness is less than $10 \mathrm{~nm}$ [33].The extended $\pi$-conjugation inside the MOFs nanosheets [110] ensures the highest electrical conductivity among other categories of MOFs reported [111, 112]. It makes 2D MOFs suitable for the next-generation electronic devices.

During the last two decades, various preparation methods have been well established and, therefore, a large number of MOFs have been synthesized with different morphology [113, 114]. In addition to the synthesis and application of pure MOFs, researchers also paid attention to the MOFs-based composites with polymer matrices. The porous structure of the 2D MOFs can be used for gas separation and storage [33]. Moreover, the good flexibility of the 2D MOFs give them chances to fabricate the advanced flexible gas separation and storage devices. Conventional preparation methods of MOFsbased polymers include two categories: (1) MOFs are formed on the template of polymers [112]; (2) polymers are added into presynthesized MOFs with polymerization [115]. Calvez et al. [116] reported a convenient way to synthesize MOFsbased polymer composites in one step. The experiment 
followed the idea of precipitation polymerization, and High Internal Phase Emulsion (HIPE) served as monomer to form a polyHIPE with macroporous structure. By this method, a suitable polymer was chosen to have a good dispersity in MOF precursor solution, leading to porous MOFs-polyHIPE composites. Based on the porous structure of the composites, it is interesting to use MOFs as a filler to form a polymer membrane for the gas separation. For example, Rodenas et al. [33] demonstrated a significant improvement of the selectivity in $\mathrm{CH}_{4} / \mathrm{CO}_{2}$ separation by incorporating $\mathrm{MOF}$ (CuBDC) nanosheets within polyimide. The selectivity of $\mathrm{CH}_{4}$ to $\mathrm{CO}_{2}$ had been increased to $80 \%$ by using the $n s$-CuBDC/PI membrane (Figure 5), and this value was $60 \%$ for pure PI membrane. The more interesting finding in this work was that when the upstream pressure increased, the selectivity also showed a slight increase for $n s$-CuBDC/PI membrane, while the other composite membranes or the pure PI membrane presented an opposite change in selectivity. Bachman et al. [117]chose a better polyimide (6FDA-DAM) to incorporate MOFs $\mathrm{N}_{2}$ (dobdc) to form polymer membrane, resulting in an enhanced selectivity and permeability for ethylene/ethane. With a loading of $25 \mathrm{wt} \% \mathrm{~N}_{2}$ (dobdc) nanocrystals, the selectivity for $\left(\mathrm{C}_{2} \mathrm{H}_{4} / \mathrm{C}_{2} \mathrm{H}_{6}\right)$ of the membrane was around 5 at atmospheric pressure, which was two-folds of the separation value by using the neat polymer 6FDA-DAM. Meanwhile, the composite membrane showed great resistance in plasticization ( 20 bar for plasticization pressure).

\section{Applications of the 2D Materials/Polymer Composites in Energy Storage}

Conventional fossil fuels sources, such as petroleum oil and coal, are nonrenewable and environmentally unfriendly. The conversion of renewable energies, such as solar energy and wind energy, into electric power has become a hot research topic. Meanwhile, the demands for the storage of these conversed energies with high efficiency have increased, namely to improve both power density and energy density of the devices. To solve this problem, storing energy into electrochemical devices is one of the main strategies. The 2D materials have been widely used in electrochemical devices and demonstrated good performances. There are two main reasons: first, the restacked $2 \mathrm{D}$ materials provide a large interlayer spacing, making it easy for the insertion and extraction of ions, such as the $\mathrm{Li}^{+}, \mathrm{K}^{+}$and $\mathrm{OH}^{-}$; secondly, there are more opportunities for the ions binding to the active sites of the $2 \mathrm{D}$ materials due to their high theoretical specific surface area. For example, graphene is one of the most popular 2D materials, showing a unique structure with high specific surface area and electrical conductivity. Therefore, graphene and its derivatives perform an important role in the application of energy storage systems. Besides the research on pure 2D materials, 2D material-based polymer composites have also been used in energy storage applications. In the following section, we will discuss the use of polymer-based composites in popular energy storage systems, such as lithium-sulfur batteries (LSBs), and supercapacitors. First, we will review the 2D-based polymer composites as separators for the battery applications.
Then, the application of supercapacitors with 2D-based polymer composites acting as electrode materials will be summarized. For each aspect, the main development in 2D materials history and the challenges will be discussed.

4.1. Li-S Battery Separators. LIBs are widely used in our daily lives, such as cell-phones, laptops, and electric cars, due to its high energy density, rechargeability, and good safety. In the commercially used LIBs, $\mathrm{LiCoO}_{2}$, graphite and polymer membrane (PVDF or PP) have been used as a cathode, anode and the separator, respectively. The energy density for this LIB was $150-190 \mathrm{~W} \mathrm{~h} \mathrm{~kg}^{-1}$, while the result could be obtained up to $\sim 240 \mathrm{~W} \mathrm{~h} \mathrm{~kg}^{-1}$ for commercial LIBs [118, 119]. In recent years, the idea of using lithium batteries for vehicle applications has got much research attention because this type of battery system in vehicles will reduce the use of fossil fuels and resultantly air pollution will also be decreased. However, for vehicle applications, higher energy density (600-1300 W $\mathrm{h} \mathrm{kg}^{-1}$ ) should be provided [120]. Therefore, many advanced battery systems have been proposed and studied, such as $\mathrm{Li}$-air batteries and Li-S batteries.

As one of the most promising systems, the Li-S battery was calculated to have a theoretical energy density of $\sim 2600$ W h kg-1 [121], which was 10 -folds of the $\mathrm{LiCoO}_{2}$ cathode battery. However, the shuttle effect of sulfur is one fatal restriction for the real use of Li-S battery. The formed polysulphide $\left(\mathrm{Li}_{2} \mathrm{~S}\right)$ during cycling would be dissolved in the electrolyte and would go through the separator, leading to a sharp decrease in capacity and poor performance of cycle life of the Li-S cells. More severely, the Li-S battery will "die". Therefore, it is necessary to use a suitable separator to prevent the transfer of the polysulfide and ensure the normal diffusion of other important ions. Although porous polymer membranes are widely used for LIBs's separator such as PVDF and PP, these are not suitable candidates for the LSB system. For example, PP is considered to be a poor membrane material due to its large pore size $(\sim 100 \mathrm{~nm})$, which is not adequate for preventing the transportation of polysulfide. To overcome this problem, Zhou et al. [122] introduced a method by directly coating graphene on the surface of PP separator and the polymer composite membrane played a role in the current collector (Figure 6). The area on the separator coated by graphene provided a useful place to store the polysulfide dissolved in the electrolyte, retarding polysulfide diffusion and therefore increasing the cycle life of Li-S cells. Zhuang et al. [123] reported a novel ternary-layered structure of the separator by integrating nafion, PP, and GO together. The reason for using GO was that there were many functional groups on the surface of GO, such as carboxyl and hydroxyl group, which exhibited a strong repulsion to the polysulfide anions due to the electrostatic interaction. The decay of capacitance showed a significant reduction to $0.18 \%$ per cycle, while the reduction per cycle for pure PP separator was $0.34 \%$.

4.2. Supercapacitor Electrodes. The supercapacitor is another type of novel energy storage device with a higher power density $\left(\sim 1000 \mathrm{Wkg}^{-1}\right)$ and excellent cycling stability but lower energy density than traditional batteries [124]. Based on large power density, supercapacitors have attracted much attention 


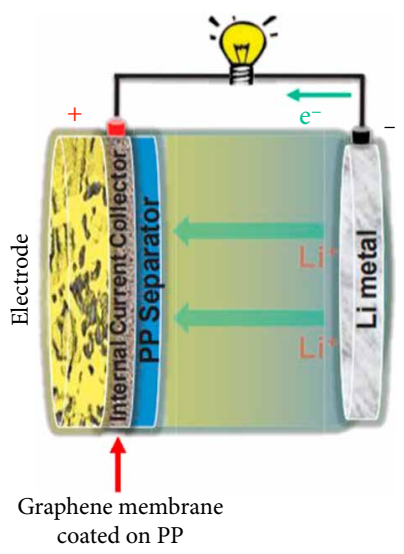

(a)

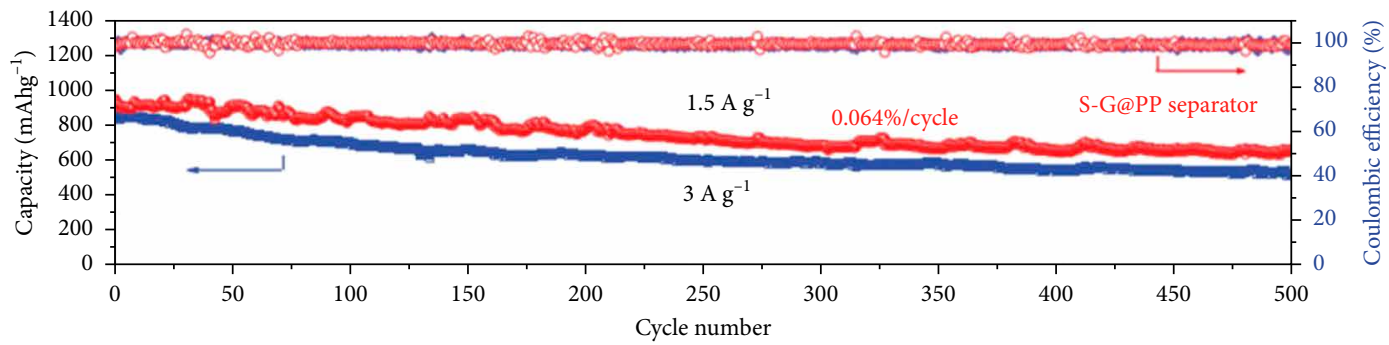

(b)

FIGURE 6: (a) Schematic illustration of electrode configuration with PP and graphene composite. (b) Cycle stability of graphene/PP separator at current density of 1.5 and $3 \mathrm{~A} \mathrm{~g}^{-1}$. Adapted from [122].

in various commercial applications, such as transportation and elevators. Supercapacitors can be divided into two categories based on different charge storage mechanisms, i.e., electric double-layer capacitor (EDLC), where the charge is absorbed on the surface, and pseudocapacitors with redox reaction occurs on the surface to store charges [124]. Generally, both mechanisms will contribute to the capacitance of the electrode material. For the materials with high pseudocapacitance, they need good conductive material to improve the stability and good charge transfer at the electrolyte/electrode interface [125]. Various conducting polymer materials have been used in supercapacitors such as polyaniline (PANi) $[54,126]$, PAN [127] and PVA, which showed good pseudocapacitance [128-130]. However, relatively poor cycling stability of these polymers restricts the application. Therefore, carbon materials such as CNTs have been first introduced to overcome this problem due to their excellent stability [131]. Later, graphenebased fillers, with remarkable electrical conductivity and excellent mechanical properties, were considered as fillers for these polymers to use in supercapacitor electrode [43]. Wang et al. [126] prepared graphene/PANi composite via in situ anodic electropolymerization. The capacitance of the composite reached $233 \mathrm{~F} \mathrm{~g}^{-1}$ generated by polyaniline films, while the electric double layer capacitance was much lower than the previous capacitance, mainly ascribed to the stacking of graphene nanosheets. However, the strong $\pi-\pi$ interaction between graphene layers makes them easily restacked, leading to the poor performance of the electrode. To avoid this problem, graphene filler has been replaced by $\mathrm{GO}$, which acts as another doped material for a polymer. Zhang et al. [54] prepared the
$\mathrm{GO} / \mathrm{PANi}$ composite by in situ polymerization, and the specific capacitance and conductivity for different GOs loading were discussed. With a loading of $10 \mathrm{wt} \%$ of GO, the conductivity of the composite achieved $231.3 \mathrm{~S} / \mathrm{m}^{-1}$, which was 20 times larger than the pure PANi. When increasing the loading of GO from 10 to 50 and $80 \mathrm{wt} \%$, a significant drop in conductivity (from 231.3 to $0.4 \mathrm{~S} / \mathrm{m}^{-1}$ ) can be seen. Also, after doping GO into $\mathrm{PANi}$, the specific capacitance decreased at the current density of $0.1 \mathrm{~A} \mathrm{~g}^{-1}$. To improve the capacitance, graphenes have been organized into three-dimensional (3D) porous structures with a high specific surface area [132]. The 3D graphene can greatly enhance the charge storage and pseudocapacitance of PANi. Tai et al. [133] prepared self-assembled 3D graphene/PANi composite hydrogel with the strategy of in situ polymerization. The specific capacitance of the composite reached $334 \mathrm{~F} \mathrm{~g}^{-1}$, which was 3-folds of the neat PANi. Kulkarni et al. [134] prepared 3D graphene by CVD on the template $\mathrm{Ni}$ and aniline monomer was added by the oxidative chemical polymerization to form 3D graphene/PANi composite. The experiment showed much higher supercapacitive performance of $\sim 1002$ $\mathrm{F} \mathrm{g}^{-1}$ (Figure 7), with the discharge current density of $1 \mathrm{~mA}$ $\mathrm{cm}^{-2}$. All these experiments demonstrated the important role of the $2 \mathrm{D}$ materials to improve the electrical conductivity and capacitance of the polymer matrix.

\section{Summary and Outlook}

In this review, we have summarized the recent progress of $2 \mathrm{D}$ materials-based polymer composites and their applications in 


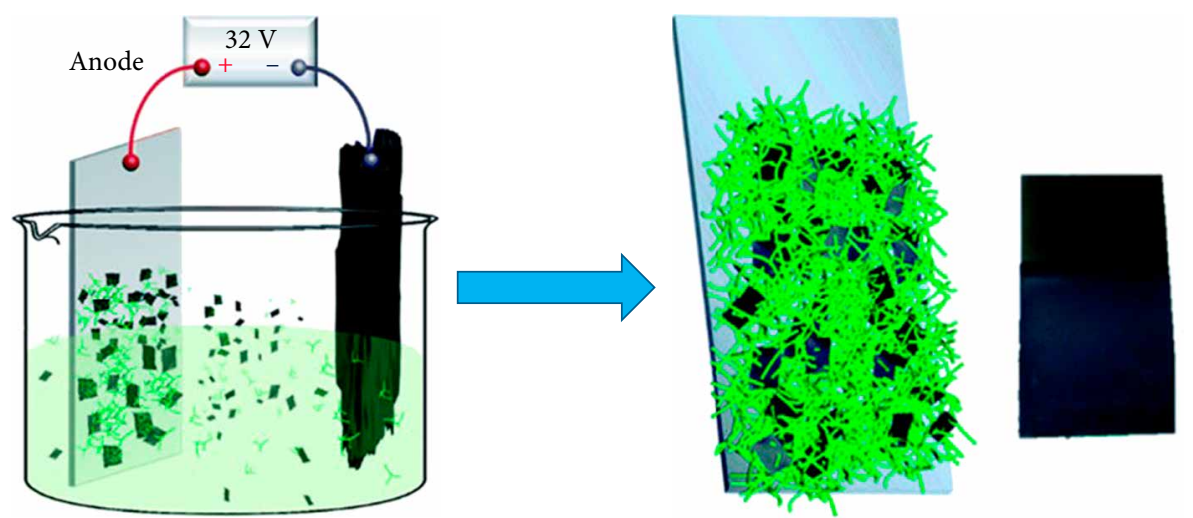

(a)

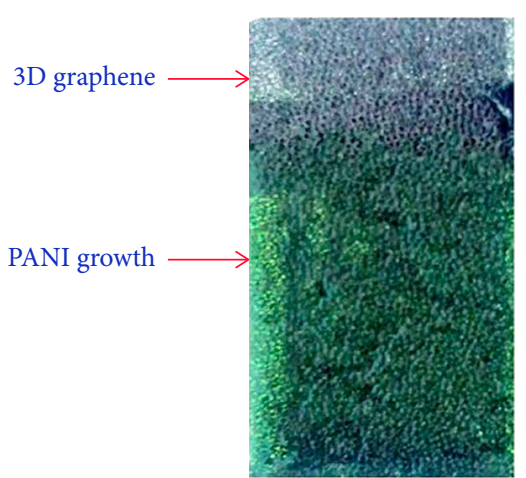

(b)

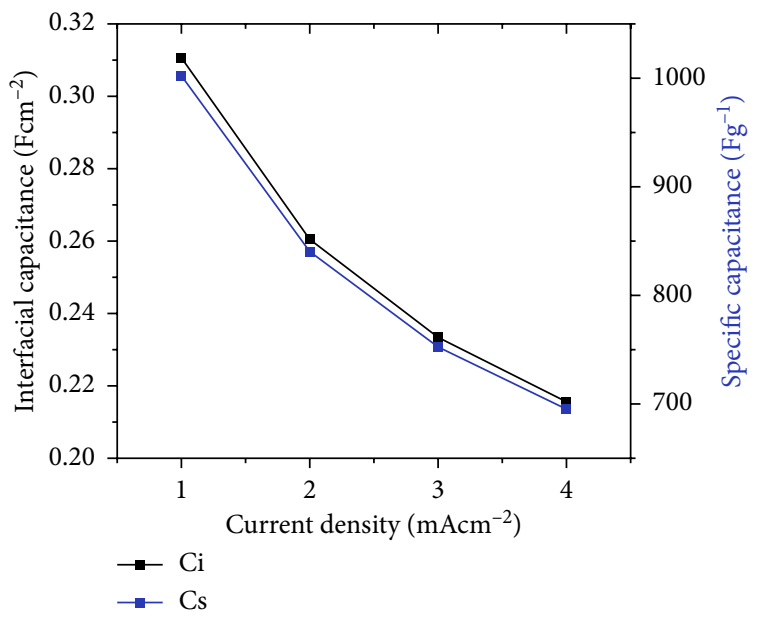

(c)

FIGURE 7: (a) Schematic illustration of the electrophoretic deposition preparation of $\mathrm{MoS}_{2} / \mathrm{PANi}$ hybrid supercapacitor electrode. Adapted from [135]. (b) Optical image of 3D graphene/PANi supercapacitor electrode. Adapted from [134]. (c) Specific capacitance of 3D graphene/ PANi is related to the current density. Adapted from [134].

energy storage systems. Firstly, we have introduced the broad applications of the polymer materials in our daily lives and the advantages of $2 \mathrm{D}$ materials as a filler to improve their properties. Then, methods to prepare the $2 \mathrm{D}$ materials-based polymer composites and their properties enhancement have been discussed. The graphene and its derivatives were used as examples to review the fabrication methods, such as solution mixing, melt intercalation, and in situ polymerization. Other 2D materials such as h-BN, $\mathrm{MoS}_{2}$ and MOF were introduced into the polymers, and their influence on properties enhancement in the polymer composites has also been discussed. Finally, the applications of 2D materials-based polymer composites in Li-S batteries and supercapacitors have been summerized. The conducting 2D-based polymer composites provide a large surface area with many active sites, leading to an excellent performance for the electrochemical reaction on the supercapacitor. For battery separator applications, both the 2D materials and polymer have porous structure, which prevents the transportation of other ions except $\mathrm{Li}^{+}$through the separators, increasing the coulombic efficiency of the batteries.

Although the enormous potential of the $2 \mathrm{D}$ materials-based polymer composites have been demonstrated in various fields, there are still many challenges in their practical applications. First, the mass production of various 2D materials is the main bottleneck in their practical applications. Although the high quality of graphene can be obtained by the scotch tape method, however, the extremely low quantity limits its practical use. Many works have been focused on the mass production of graphene for industrial applications. Currently, the problem of mass production of graphene has been solved, and many commercial applications of graphene-based polymer composites have been reported. However, for the other 2D materials-based polymer composites, the mass production of $2 \mathrm{D}$ materials is still the main challenge needed to be solved. To overcome this issue, one should focus on developing highly efficient exfoliation methods, which can exfoliate the layered materials in large scale. Then, how to balance the relationship between quality and quantity also remains a big problem. For example, h-BN-based polymer composites can be produced via ball milling with large quantities, while the size is relatively small due to the fierce collisions between the balls during the exfoliation process. Once the mass production of various $2 \mathrm{D}$ materials comes true, it will not be too long to see the 2D-based polymer composites affect our daily life.

Secondly, further exploration of multiple 2D materials-based polymer composites should be done. It is obvious to 
find that most of the studies focus on the use of a single 2D material in polymer composites, while there are merely few reports who investigated the polymer composites by adding more than one $2 \mathrm{D}$ materials together. In principle, each $2 \mathrm{D}$ material has its unique properties but with several drawbacks. For example, graphene has high electrical conductivity and large theoretical specific area, which prefers to be used as a conductive filler for the energy storage device. However, it has been reported that the graphene-based polymer composites exhibit very low energy density. To overcome this problem, the idea of mixing graphene with other 2D materials was proposed [136]. For example, 2D oxide nanosheets with suitable capacitance could be added into polymer composites with graphene together, and the energy density of the resulting $2 \mathrm{D}$ polymer composites will be improved and they can be integrated to electrodes because of the polymers.

The polymers have penetrated every aspect of our daily life, and their properties enhancement will greatly influence the development of industrial, medicinal, and other various fields. As a recently developed material, 2D materials have a great chance to tune the mechanical, electrical, and thermal properties of polymers even with little amounts of them. We believe the effort spent on the exfoliation of $2 \mathrm{D}$ materials and the study of the 2D materials-based composites deserves to be made both for fundamental research and practical applications.

\section{Abbreviations}

$\begin{array}{ll}\text { PP: } & \text { Polypropylene } \\ \text { PMMA: } & \text { Polymethyl methacrylate } \\ \text { PPy: } & \text { polypyrrole } \\ \text { PEI: } & \text { Polyetherimide } \\ \text { PI: } & \text { polyimide } \\ \text { PEO: } & \text { Poly(ethylene oxide) } \\ \text { TPU: } & \text { Thermoplastic polyurethane } \\ \text { PVDF: } & \text { Poly(vinylidene fluoride) } \\ \text { PVA: } & \text { Poly(vinyl alcohol) } \\ \text { PAN: } & \text { Poly(acrylonitrile) } \\ \text { PANi: } & \text { Polyaniline } \\ \text { PS: } & \text { Polystyrene } \\ \text { PET: } & \text { Polyethylene terephthalate } \\ \text { h-BN: } & \text { Hexagonal boron nitride } \\ \text { CNTs: } & \text { Carbon nanotubes } \\ \text { SWCNT: } & \text { Single-wall carbon nanotube } \\ \text { MWCNT: } & \text { Multi-walled carbon nanotubes } \\ \text { GO: } & \text { Graphene oxide } \\ \text { TMDCs: } & \text { Transition metal dichalcogenides } \\ \text { MOFs: } & \text { Metal-organic frameworks } \\ \text { EG: } & \text { Expanded graphite } \\ \text { FGS: } & \text { Functionalized graphene sheets. } \\ & \end{array}$

\section{Conflicts of Interest}

The authors declare that they have no conflicts of interest.

\section{Acknowledgments}

X. Cai thanks the financial supports from the Guangdong University Young Talents Project (No. 2018KQNCX218), NTUT-SZU Joint Research Program (No. 2019001), and Research Start-Up Fund of Shenzhen University (No. 2019017).

\section{References}

[1] H. M. De Azeredo, "Nanocomposites for food packaging applications," Food Research International, vol. 42, no. 9, pp. 1240-1253, 2009.

[2] E. J. Markvicka, M. D. Bartlett, X. Huang, and C. Majidi, "An autonomously electrically self-healing liquid metal-elastomer composite for robust soft-matter robotics and electronics," Nature Materials, vol. 17, no. 7, pp. 618-624, 2018.

[3] M. P. Indumathi and G. R. Rajarajeswari, "Mahua oil-based polyurethane/chitosan/nano $\mathrm{ZnO}$ composite films for biodegradable food packaging applications," International Journal of Biological Macromolecules, vol. 124, pp. 163-174, 2019.

[4] T. Tagami, N. Nagata, N. Hayashi et al., "Defined drug release from 3D-printed composite tablets consisting of drug-loaded polyvinylalcohol and a water-soluble or water-insoluble polymer filler," International Journal of Pharmaceutics, vol. 543, p. 361, 2018.

[5] K. Wakabayashi, C. Pierre, D. A. Dikin et al., "Polymergraphite nanocomposites: effective dispersion and major property enhancement via solid-state shear pulverization," Macromolecules, vol. 41, no. 6, pp. 1905-1908, 2008.

[6] K. I. Winey and R. A. Vaia, "Polymer nanocomposites," MRS Bulletin, vol. 32, no. 4, pp. 314-322, 2007.

[7] A. C. Balazs, T. Emrick, and T. P. Russell, "Nanoparticle polymer composites: where two small worlds meet," Science, vol. 314, no. 5802, pp. 1107-1110, 2006.

[8] D. Y. Godovsky, In Biopolymers.PVA Hydrogels, Anionic Polymerisation Nanocomposites, Springer, Berlin, Heidelberg, 2000.

[9] T. Kuilla, S. Bhadra, D. Yao, N. H. Kim, S. Bose, and J. H. Lee, "Recent advances in graphene based polymer composites," Progress in Polymer Science, vol. 35, no. 11, pp. 1350-1375, 2010.

[10] J. N. Coleman, U. Khan, W. J. Blau, and Y. K. Gun'ko, "Small but strong: a review of the mechanical properties of carbon nanotube-polymer composites," Carbon, vol. 44, no. 9, pp. 1624-1652, 2006.

[11] Z. Spitalsky, D. Tasis, K. Papagelis, and C. Galiotis, "Carbon nanotube-polymer composites: chemistry, processing, mechanical and electrical properties," Progress in Polymer Science, vol. 35, no. 3, pp. 357-401, 2010.

[12] S. Stankovich, D. A. Dikin, G. H. Dommett et al., "Graphenebased composite materials," Nature, vol. 442, no. 7100, pp. 282-286, 2006.

[13] H. Liu, Q. Li, S. Zhang et al., "Highly efficient uranium adsorption by salicylaldoxime/polydopamine graphene oxide nanocomposites," Journal of Materials Chemistry, vol. 6, no. 48, p. 12121, 2018. 
[14] D. M. Bigg, "Mechanical, thermal, and electrical properties of metal fiber-filled polymer composites," Polymer Engineering \& Science, vol. 19, no. 16, pp. 1188-1192, 1979.

[15] B. P. Singh, B. K. Jena, S. Bhattacharjee, and L. Besra, "Development of oxidation and corrosion resistance hydrophobic graphene oxide-polymer composite coating on copper," Surface and Coatings Technology, vol. 232, pp. 475-481, 2013.

[16] B. Wetzel, F. Haupert, K. Friedrich, M. Q. Zhang, and M. Z. Rong, "Impact and wear resistance of polymer nanocomposites at low filler content," Polymer Engineering \& Science, vol. 42, no. 9, pp. 1919-1927, 2002.

[17] W. Zhou, S. Qi, Q. An, H. Zhao, and N. Liu, "Thermal conductivity of boron nitride reinforced polyethylene composites," Materials Research Bulletin, vol. 42, no. 10, pp. 1863-1873, 2007.

[18] W. P. Lin, S. J. Liu, T. Gong, Q. Zhao, and W. Huang, "Polymerbased resistive memory materials and devices," Advanced Materials, vol. 26, no. 4, pp. 570-606, 2014.

[19] Y. Zhang, C. Zhang, Y. Feng et al., "Excellent energy storage performance and thermal property of polymer-based composite induced by multifunctional one-dimensional nanofibers oriented in-plane direction," Nano Energy, vol. 56, pp. 138-150, 2019.

[20] N. Saba, P. Tahir, and M. Jawaid, "A review on potentiality of nano filler/natural fiber filled polymer hybrid composites," Polymers, vol. 6, no. 8, pp. 2247-2273, 2014.

[21] R. Roy, S. Komarneni, and D. M. Roy, "Multi-phasic ceramic composites made by sol-gel technique," MRS Online Proceedings Library Archive, vol. 32, p. 347, 1984.

[22] M. Z. Rong, M. Q. Zhang, and W. H. Ruan, "Surface modification of nanoscale fillers for improving properties of polymer nanocomposites: a review," Materials Science and Technology, vol. 22, no. 7, pp. 787-796, 2006.

[23] S. Shi, D. Shen, T. Xu, and Y. Zhang, "Science direct," Composites Science and Technology, vol. 164, 17 pages, 2018.

[24] R. M. Mutiso and K. I. Winey, "Electrical properties of polymer nanocomposites containing rod-like nanofillers," Progress in Polymer Science, vol. 40, pp. 63-84, 2015.

[25] M. Z. Rong, M. Q. Zhang, Y. X. Zheng, H. M. Zeng, and K. Friedrich, "Improvement of tensile properties of nano- $\mathrm{SiO}_{2} /$ PP composites in relation to percolation mechanism," Polymer, vol. 42, no. 7, pp. 3301-3304, 2001.

[26] M. Avella, M. E. Errico, and E. Martuscelli, "Novel PMMA/ $\mathrm{CaCO}_{3}$ nanocomposites abrasion resistant prepared by an in situ polymerization process," Nano letters, vol. 1, no. 4, pp. 213-217, 2001.

[27] C. Tan, X. Cao, X.-J. Wu et al., "Recent advances in ultrathin two-dimensional nanomaterials," Chemical Reviews, vol. 117, no. 9, pp. 6225-6331, 2017.

[28] C. Huo, Z. Yan, X. Song, and H. Zeng, "2D materials via liquid exfoliation: a review on fabrication and applications," Science Bulletin, vol. 2015, p. 60, 1994.

[29] A. K. Geim, “Graphene: status and prospects," Science, vol. 324, no. 5934, pp. 1530-1534, 2009.

[30] G. Eda, Y. Y. Lin, C. Mattevi et al., "Blue photoluminescence from chemically derived graphene oxide," Advanced Materials, vol. 22, no. 4, p. 2392, 2010.

[31] C. Zhi, Y. Bando, C. Tang, H. Kuwahara, and D. Golberg, "Large-scale fabrication of boron nitride nanosheets and their utilization in polymeric composites with improved thermal and mechanical properties," Advanced Materials, vol. 21, no. 28, pp. 2889-2893, 2009.

[32] Q. H. Wang, K. Kalantar-Zadeh, A. Kis, J. N. Coleman, and M. S. Strano, "Electronics and optoelectronics of two-dimensional transition metal dichalcogenides," Nature Nanotechnology, vol. 7, no. 11, pp. 699-712, 2012.

[33] T. Rodenas, I. Luz, G. Prieto et al., "Metal-organic framework nanosheets in polymer composite materials for gas separation," Nature Materials, vol. 14, no. 1, pp. 48-55, 2014.

[34] X. Cai, Y. Luo, B. Liu, and H.-M. Cheng, "Preparation of 2D material dispersions and their applications," Chemical Society Reviews, vol. 47, no. 16, pp. 6224-6266, 2018.

[35] Y. Jung, Y. Zhou, and J. J. Cha, "Intercalation in two-dimensional transition metal chalcogenides," Inorganic Chemistry Frontiers, vol. 3, no. 4, pp. 452-463, 2016.

[36] V. Nicolosi, M. Chhowalla, M. G. Kanatzidis, M. S. Strano, and J. N. Coleman, "Liquid exfoliation of layered materials," Science, vol. 340, no. 6139, 1226419 pages, 2013.

[37] M. Naguib, M. Kurtoglu, V. Presser et al., "Two-dimensional nanocrystals produced by exfoliation of Ti3AlC2," Advanced Materials, vol. 23, no. 37, pp. 4248-4253, 2011.

[38] W. Guo and G. Chen, "Crystallization kinetics of poly(3-hydroxybutyrate-co-3-hydroxyvalerate)/clay nanocomposites," Journal of Applied Polymer Science, p. 131, 2014.

[39] Z. Zeng, Z. Yin, X. Huang et al., "Single-layer semiconducting nanosheets: high-yield preparation and device fabrication," Angewandte Chemie International Edition, vol. 50, p. 11093, 2011.

[40] T. Sasaki, M. Watanabe, H. Hashizume, H. Yamada, and H. Nakazawa, "Macromolecule-like aspects for a colloidal suspension of an exfoliated titanate. Pairwise association of nanosheets and dynamic reassembling process initiated from it," Journal of the American Chemical Society, vol. 118, no. 35, pp. 8329-8335, 1996.

[41] K. S. Novoselov, A. K. Geim, S. V. Morozov et al., "Electric field effect in atomically thin carbon films," Science, vol. 306, no. 5696, pp. 666-669, 2004.

[42] C. Lee, X. Wei, J. W. Kysar, and J. Hone, "Measurement of the elastic properties and intrinsic strength of monolayer graphene," Science, vol. 321, pp. 385-388, 2008.

[43] M. D. Stoller, S. Park, Y. Zhu, J. An, and R. S. Ruoff, "Graphenebased ultracapacitors," Nano Letters, vol. 8, no. 10, pp. 34983502, 2008.

[44] R. R. Nair, P. Blake, A. N. Grigorenko et al., "Fine structure constant defines visual transparency of graphene," Science, vol. 320, no. 5881, p. 1308, 2008.

[45] A. A. Balandin, S. Ghosh, W. Bao et al., "Superior thermal conductivity of single-layer graphene," Nano Letters, vol. 8, no. 3, pp. 902-907, 2008.

[46] D. R. Dreyer, S. Park, C. W. Bielawski, and R. S. Ruoff, "The chemistry of graphene oxide," Chemical Society Reviews, vol. 39, no. 1, pp. 228-240, 2010.

[47] N. A. Kotov, "Nanostructured artificial nacre," Nature, vol. 442, p. 254, 2006.

[48] Y. Hernandez, V. Nicolosi, M. Lotya et al., "High-yield production of graphene by liquid-phase exfoliation of graphite," Nature Nanotechnology, vol. 3, no. 9, pp. 563-568, 2008. 
[49] Y. Xu, W. Hong, H. Bai, C. Li, and G. Shi, "Strong and ductile poly (vinyl alcohol)/graphene oxide composite films with a layered structure," Carbon, vol. 47, no. 15, pp. 3538-3543, 2009.

[50] D. Cai and M. Song, "The mechanical properties and morphology of a graphite oxide nanoplatelet/polyurethane composite," Nanotechnology, vol. 20, no. 8, p. 315708, 2009.

[51] Q. Wu, Y. Xu, Z. Yao, A. Liu, and G. Shi, "Supercapacitors based on flexible graphene/polyaniline nanofiber composite films," ACS Nano, vol. 4, no. 4, pp. 1963-1970, 2010.

[52] Z. Lin, A. McNamara, Y. Liu, K. S. Moon, and C. P. Wong, "Exfoliated hexagonal boron nitride-based polymer nanocomposite with enhanced thermal conductivity for electronic encapsulation," Composites Science and Technology, vol. 90, pp. 123-128, 2014.

[53] A. Yu, P. Ramesh, M. E. Itkis, E. Bekyarova, and R. C. Haddon, "Graphite nanoplatelet-epoxy composite thermal interface materials," The Journal of Physical Chemistry, vol. 111, pp. 7565-7569, 2007.

[54] K. Zhang, L. L. Zhang, X. S. Zhao, and J. Wu, "Graphene/ polyaniline nanofiber composites as supercapacitor electrodes," Chemistry of Materials, vol. 22, no. 4, pp. 1392-1401, 2010.

[55] Y. Guo, G. Xu, X. Yang et al., "Significantly enhanced and precisely modeled thermal conductivity in polyimide nanocomposites with chemically modified graphene via in situ polymerization and electrospinning-hot press technology," Journal of Materials Chemistry C, vol. 6, no. 12, pp. 3004-3015, 2018.

[56] P. Fan, L. Wang, J. Yang, F. Chen, and M. Zhong, "Graphene/ poly(vinylidene fluoride) composites with high dielectric constant and low percolation threshold," Nanotechnology, vol. 23, no. 36, 365702 pages, 2012.

[57] J. A. Throckmorton, A. L. Watters, X. Geng, and G. R. Palmese, "Room temperature ionic liquids for epoxy nanocomposite synthesis: direct dispersion and cure," Composites Science and Technology, vol. 86, pp. 38-44, 2013.

[58] H. Gómez, M. K. Ram, F. Alvi, P. Villalba, E. Stefanakos, and A. Kumar, "Graphene-conducting polymer nanocomposite as novel electrode for supercapacitors," Journal of Power Sources, vol. 196, no. 8, pp. 4102-4108, 2011.

[59] W. Zheng, X. Lu, and S. C. Wong, "Electrical and mechanical properties of expanded graphite-reinforced high-density polyethylene," Journal of Applied Polymer Science, vol. 91, p. 2781, 2004.

[60] H. Hu, X. Wang, J. Wang et al., "Preparation and properties of graphene nanosheets-polystyrene nanocomposites via in situ emulsion polymerization," Chemical Physics Letters, vol. 484, no. 4-6, pp. 247-253, 2010.

[61] S. Ansari and E. P. Giannelis, "Femtosecond laser writing of PPV-doped three-dimensional polymeric microstructures," Journal of Polymer Science Part B: Polymer Physics, vol. 47, p. 888, 2009.

[62] J. Liang, Y. Huang, L. Zhang et al., "Molecular-level dispersion of graphene into poly (vinyl alcohol) and effective reinforcement of their nanocomposites," Advanced Functional Materials, vol. 19, no. 14, pp. 2297-2302, 2009.

[63] O. M. Istrate, K. R. Paton, U. Khan, A. O’Neill, A. P. Bell, and J. N. Coleman, "Reinforcement in melt-processed polymergraphene composites at extremely low graphene loading level," Carbon, vol. 78, pp. 243-249, 2014.

[64] R. A. Vaia, H. Ishii, and E. P. Giannelis, "Synthesis and properties of two-dimensional nanostructures by direct intercalation of polymer melts in layered silicates," Chemistry of Materials, vol. 5, no. 12, pp. 1694-1696, 1993.

[65] Y. Guo, F. Peng, H. Wang et al., "Intercalation polymerization approach for preparing graphene/polymer composites," Polymers, vol. 10, no. 1, p. 61, 2018.

[66] K. Kalaitzidou, H. Fukushima, and L. T. Drzal, "A new compounding method for exfoliated graphite-polypropylene nanocomposites with enhanced flexural properties and lower percolation threshold," Composites Science and Technology, vol. 67, no. 10, pp. 2045-2051, 2007.

[67] K. Kalaitzidou, H. Fukushima, and L. T. Drzal, "Mechanical properties and morphological characterization of exfoliated graphite-polypropylene nanocomposites," Composites Part A: Applied Science and Manufacturing, vol. 38, no. 7, pp. 16751682, 2007.

[68] N. Grossiord, H. E. Miltner, J. Loos, J. Meuldijk, B. Van Mele, and C. E. Koning, "On the crucial role of wetting in the preparation of conductive polystyrene-carbon nanotube composites," Chemistry of Materials, vol. 19, no. 15, pp. 37873792, 2007.

[69] R. B. Mathur, S. Pande, B. P. Singh, and T. L. Dhami, "Designing of epoxy composites reinforced with carbon nanotubes grown carbon fiber fabric for improved electromagnetic interference shielding," Polymer Composites, vol. 29, p. 717, 2008.

[70] G.-H. Chen, D.-J. Wu, W.-G. Weng, B. He, and W.-L. Yan, "Preparation of polymer/graphite conducting nanocomposite by intercalation polymerization," Polymer International, vol. 50, p. 980, 2001.

[71] N. Liu, F. Luo, H. Wu, Y. Liu, C. Zhang, and J. Chen, "Onestep ionic-liquid-assisted electrochemical synthesis of ionicliquid-functionalized graphene sheets directly from graphite," Advanced Functional Materials, vol. 18, p. 1518, 2008.

[72] X.-Y. Qi, D. Yan, Z. Jiang et al., "Enhanced electrical conductivity in polystyrene nanocomposites at ultra-low graphene content," ACS Applied Materials \& Interfaces, vol. 3, no. 8, pp. 3130-3133, 2011.

[73] H. B. Zhang, W. G. Zheng, Q. Yan et al., "Electrically conductive polyethylene terephthalate/graphene nanocomposites prepared by melt compounding," Polymer, vol. 51, no. 5, pp. 1191-1196, 2010.

[74] G. Chen, W. Weng, D. Wu, and C. Wu, "PMMA/graphite nanosheets composite and its conducting properties," European Polymer Journal, vol. 39, no. 12, pp. 2329-2335, 2003.

[75] S. Stankovich, D. A. Dikin, G. H. B. Dommett et al., "Graphenebased composite materials," Nature, vol. 442, no. 7100, p. 282, 2006.

[76] T. Ramanathan, A. A. Abdala, S. Stankovich et al., "Functionalized graphene sheets for polymer nanocomposites," Nature Nanotechnology, vol. 3, pp. 327-331, 2008.

[77] A. Satti, P. Larpent, and Y. Gun'ko, "Lubrication of poly(vinyl alcohol) chain orientation by carbon nano-chips in composite tapes," Carbon, vol. 48, p. 3376, 2010.

[78] P. Dash, T. Dash, T. K. Rout, A. K. Sahu, S. K. Biswal, and B. K. Mishra, "Preparation of graphene oxide by dry planetary ball milling process from natural graphite," RSC Advances, vol. 6, no. 15, pp. 12657-12668, 2016.

[79] W. Xu, C. Wei, J. Lv, H. Liu, X. Huang, and T. Liu, "Preparation, characterization, and properties of in situ formed grapheme oxide/phenol formaldehyde nanocomposites," Journal of Nanomaterials, vol. 2013, 86 pages, 2013. 
[80] Y. Geng, S. J. Wang, and J.-K. Kim, "Preparation of graphite nanoplatelets and graphene sheets," Journal of Colloid and Interface Science, vol. 336, no. 2, pp. 592-598, 2009.

[81] K. A. Worsley, P. Ramesh, S. K. Mandal, S. Niyogi, M. E. Itkis, and R. C. Haddon, "Soluble graphene derived from graphite fluoride," Chemical Physics Letters, vol. 445, no. 1-3, pp. 51-56, 2007.

[82] A. Satti, P. Larpent, and Y. Gun'ko, "Lubrication of poly(vinyl alcohol) chain orientation by carbon nano-chips in composite tapes," Carbon, vol. 48, p. 3376, 2010.

[83] S. Chatterjee, J. W. Wang, W. S. Kuo et al., "Mechanical reinforcement and thermal conductivity in expanded graphene nanoplatelets reinforced epoxy composites," Chemical Physics Letters, vol. 531, pp. 6-10, 2012.

[84] T. Zhou, H. Koga, M. Nogi et al., "Targeted kinetic strategy for improving the thermal conductivity of epoxy composite containing percolating multi-layer graphene oxide chains," Express Polymer Letters, vol. 9, no. 7, p. 608, 2015.

[85] G. Chen, W. Weng, D. Wu, and C. Wu, "PMMA/graphite nanosheets composite and its conducting properties," European Polymer Journal, vol. 39, no. 12, pp. 2329-2335, 2003.

[86] L.-C. Tang, Y.-J. Wan, D. Yan et al., "The effect of graphene dispersion on the mechanical properties of graphene/epoxy composites," Carbon, vol. 60, pp. 16-27, 2013.

[87] A. Idowu, B. Boesl, and A. Agarwal, "3D graphene foamreinforced polymer composites - a review," Carbon, vol. 135, pp. 52-71, 2018.

[88] L.-Z. Guan, L. Zhao, Y.-J. Wan, and L.-C. Tang, "Threedimensional graphene-based polymer nanocomposites: preparation, properties and applications," Nanoscale, vol. 10, no. 31, pp. 14788-14811, 2018.

[89] W. Ouyang, J. Sun, J. Memon, C. Wang, J. Geng, and Y. Huang, "Scalable preparation of three-dimensional porous structures of reduced graphene oxide/cellulose composites and their application in supercapacitors," Carbon, vol. 62, pp. 501-509, 2013.

[90] Z. Wang, X. Shen, N. M. Han et al., "Ultralow electrical percolation in graphene aerogel/epoxy composites," Chemistry of Materials, vol. 28, no. 18, pp. 6731-6741, 2016.

[91] J. Liu, Z. Wang, Y. Zhao et al., "Three-dimensional graphenepolypyrrole hybrid electrochemical actuator," Nanoscale, vol. 4, no. 23, pp. 7563-7568, 2012.

[92] H. Li, L. Liu, and F. Yang, "Nitrogen-doped reduced graphene oxide for high-performance flexible all-solid-state microsupercapacitors," Journal of Materials Chemistry A, vol. 1, p. 3446, 2013.

[93] J. Jia, X. Sun, X. Lin, X. Shen, Y.-W. Mai, and J.-K. Kim, "Exceptional electrical conductivity and fracture resistance of 3D interconnected graphene foam/epoxy composites," ACS Nano, vol. 8, no. 6, pp. 5774-5783, 2014.

[94] J. Gao, J. Yu, X. Wu et al., "Enhanced thermal properties for epoxy composites with a three-dimensional graphene oxide filler," Fibers and Polymers, vol. 16, no. 12, pp. 2617-2626, 2015.

[95] W.-L. Song, P. Wang, L. Cao et al., Angewandte Chemie International Edition, vol. 51, no. 26, pp. 6498-6501, 2012.

[96] T. L. Li and S. L. C. Hsu, "Enhanced thermal conductivity of polyimide films via a hybrid of micro-and nano-sized boron nitride," The Journal of Physical Chemistry B, vol. 114, no. 20, pp. 6825-6829, 2010.
[97] K. Yung and H. Liem, "Enhanced thermal conductivity of boron nitride epoxy-matrix composite through multi-modal particle size mixing," Journal of Applied Polymer Science, vol. 106, p. 3587, 2007.

[98] V. Guerra, C. Wan, and T. McNally, "Thermal conductivity of 2D nano-structured boron nitride (BN) and its composites with polymers," Progress in Materials Science, vol. 100, 170 pages, 2018.

[99] T. L. Li and S. L. C. Hsu, "Preparation and properties of thermally conductive photosensitive polyimide/boron nitride nanocomposites," Journal of Applied Polymer Science, vol. 121, no. 2, pp. 916-922, 2011.

[100] K. Sato, H. Horibe, T. Shirai et al., Journal of Materials Chemistry, vol. 20, p. 2749, 2010.

[101] K. Wattanakul, H. Manuspiya, and N. Yanumet, "Effective surface treatments for enhancing the thermal conductivity of BN-filled epoxy composite," Journal of Applied Polymer Science, vol. 119, no. 6, pp. 3234-3243, 2011.

[102] H. L. Lee, O. H. Kwon, S. M. Ha et al., "Thermalconductivity improvement of surface-enhanced polyetherimide (PEI) composites using polyimide-coated h-BN particles," Physical Chemistry Chemical Physics, vol. 16, no. 37, pp. 20041-20046, 2014.

[103] A. V. Murugan, M. Quintin, M.-H. Delville, G. Campet, C. S. Gopinath, and K. Vijayamohanan, "Exfoliation-induced nanoribbon formation of poly (3, 4-ethylene dioxythiophene) PEDOT between $\mathrm{MoS}_{2}$ layers as cathode material for lithium batteries," Journal of Power Sources, vol. 156, no. 2, pp. 615-619, 2006.

[104] J. Xiao, D. Choi, L. Cosimbescu, P. Koech, J. Liu, and J. P. Lemmon, "Exfoliated $\mathrm{MoS}_{2}$ nanocomposite as an anode material for lithium ion batteries," Chemistry of Materials, vol. 22, no. 16, pp. 4522-4524, 2010.

[105] J. Guo, D. Xie, B. Yang, and J. Jiang, "Mode selectivity in methane dissociative chemisorption on $\mathrm{Ni}(111)$," Solid-State Electronics, vol. 144, p. 1, 2018.

[106] J. Guo, J. Jiang, Z. Zheng, and B. Yang, "Insight into negative differential resistance in polyphenylene molecular device with graphene electrodes," Organic Electronics, vol. 40, p. 75, 2017.

[107] G. Ma, H. Peng, J. Mu, H. Huang, X. Zhou, and Z. Lei, “The international journal on the science and technology of electrochemical energy systems," Journal of Power Sources, vol. 229, p. 72, 2013.

[108] S. Kitagawa, "Metal-organic frameworks (MOFs)," Chemical Society Reviews, vol. 43, p. 5415, 2014.

[109] G. Férey, "The new age of MOFs and of their porous-related solids," Chemical Society Reviews, vol. 37, p. 191, 2008.

[110] R. Gutzler and D. F. Perepichka, " $\pi$-electron conjugation in two dimensions," Journal of the American Chemical Society, vol. 135, p. 16585, 2013.

[111] Y. Kobayashi, B. Jacobs, M. D. Allendorf, and J. R. Long, "Conductivity, doping, and redox chemistry of a microporous dithiolene-based metal-organic framework," Chemistry of Materials, vol. 22, no. 14, pp. 4120-4122, 2010.

[112] A. A. Talin, A. Centrone, A. C. Ford et al., "Tunable electrical conductivity in metal-organic framework thin-film devices," Science, vol. 343, no. 6166, pp. 66-69, 2014.

[113] L. D. O'Neill, H. Zhang, and D. Bradshaw, "Macro-/ microporous MOF composite beads," Journal of Materials Chemistry, vol. 20, no. 27, pp. 5720-5726, 2010. 
[114] J. Huo, M. Marcello, A. Garai, and D. Bradshaw, "MOF-polymer composite microcapsules derived from pickering emulsions," Advanced Materials, vol. 25, no. 19, pp. 2717-2722, 2013.

[115] M. G. Schwab, I. Senkovska, M. Rose et al., "MOF@ polyHIPEs," Advanced Engineering Materials, vol. 10, no. 12, pp. 1151-1155, 2008.

[116] C. Le Calvez, M. Zouboulaki, C. Petit, L. Peeva, and N. Shirshova, "One step synthesis of MOF-polymer composites," RSC Advances, vol. 6, no. 21, pp. 17314-17317, 2016.

[117] J. E. Bachman, Z. P. Smith, T. Li, T. Xu, and J. R. Long, "Enhanced ethylene separation and plasticization resistance in polymer membranes incorporating metal-organic framework nanocrystals," Nature Materials, vol. 15, no. 8, p. 845, 2016.

[118] A. B. Yaroslavtsev, T. Kulova, and A. M. Skundin, "Electrode nanomaterials for lithium-ion batteries," Russian Chemical Reviews, vol. 84, no. 8, p. 826, 2015.

[119] P. G. Bruce, S. A. Freunberger, L. J. Hardwick, and J.-M. Tarascon, " $\mathrm{Li}-\mathrm{O}_{2}$ and $\mathrm{Li}-\mathrm{S}$ batteries with high energy storage," Nature Materials, vol. 11, no. 1, p. 19, 2011.

[120] A. Khaligh and Z. Li, "Battery, ultracapacitor, fuel cell, and hybrid energy storage systems for electric, hybrid electric, fuel cell, and plug-in hybrid electric vehicles: State of the art," IEEE transactions on Vehicular Technology, vol. 59, no. 6, pp. 2806-2814, 2010.

[121] R. Cao, W. Xu, D. Lv, J. Xiao, and J.-G. Zhang, "Anodes for rechargeable lithium-sulfur batteries," Advanced Energy Materials, vol. 5, no. 16, p. 1402273, 2015.

[122] G. Zhou, L. Li, D.-W. Wang et al., "A flexible sulfur-graphenepolypropylene separator integrated electrode for advanced Li-S batteries," Advanced Materials, vol. 27, no. 4, pp. 641-617, 2015.

[123] T. Z. Zhuang, J. Q. Huang, H. J. Peng et al., "Rational integration of polypropylene/graphene oxide/nafion as ternary-layered separator to retard the shuttle of polysulfides for lithium-sulfur batteries," Small, vol. 12, no. 3, pp. 381-389, 2016.

[124] P. Simon and Y. Gogotsi, Nanoscience and Technology, CoPublished with Macmillan Publishers Ltd, UKp. 320, 2009.

[125] B. Conway and W. Pell, "Twenty years of the journal of solid state electrochemistry," Journal of Solid State Electrochemistry, vol. 7, p. 637, 2003.

[126] D.-W. Wang, F. Li, J. Zhao et al., "Fabrication of graphene/polyaniline composite paper via in situ anodic electropolymerization for high-performance flexible electrode," ACS Nano, vol. 3, no. 7, pp. 1745-1752, 2009.

[127] A. S. Levitt, M. Alhabeb, C. B. Hatter, A. Sarycheva, G. Dion, and Y. Gogotsi, "Electrospun MXene/carbon nanofibers as supercapacitor electrodes," Journal of Materials Chemistry A, vol. 7, p. 269, 2019.

[128] Z. Ling, C. E. Ren, M. Q. Zhao et al., "Flexible and conductive MXene films and nanocomposites with high capacitance," Proceedings of the National Academy of Sciences, vol. 111, no. 47, pp. 16676-16681, 2014.

[129] A. Rose, K. G. Prasad, T. Sakthivel, V. Gunasekaran, T. Maiyalagan, and T. Vijayakumar, "Electrochemical analysis of graphene oxide/polyaniline/polyvinyl alcohol composite nanofibers for supercapacitor applications," Applied Surface Science, vol. 449, pp. 551-557, 2018.

[130] G. A. Snook, P. Kao, and A. S. Best, "Conducting-polymerbased supercapacitor devices and electrodes," Journal of Power Sources, vol. 196, p. 1, 2011.
[131] E. Frackowiak, V. Khomenko, K. Jurewicz, K. Lota, and F. Béguin, "Supercapacitors based on conducting polymers/ nanotubes composites," Journal of Power Sources, vol. 153, no. 2, pp. 413-418, 2006.

[132] X. Cao, Y. Shi, W. Shi et al., "Preparation of novel 3D graphene networks for supercapacitor applications," Small, vol. 7, no. 22, pp. 3163-3168, 2011

[133] Z. Tai, X. Yan, and Q. Xue, "Mutually enhanced capacitances in carbon nanofiber/cobalt hydroxide composite paper for supercapacitor," Journal of The Electrochemical Society, vol. 159, no. 4, p. A1702, 2012.

[134] S. B. Kulkarni, U. M. Patil, I. Shackery et al., "High-performance supercapacitor electrode based on a polyaniline nanofibers/3D graphene framework as an efficient charge transporter," Journal of Materials Chemistry A, vol. 2, no. 14, pp. 4989-4998, 2014.

[135] M. S. Nam, U. Patil, B. Park, H. B. Sim, and S. C. Jun, "A binder free synthesis of $1 \mathrm{D}$ PANI and 2D MoS 2 nanostructured hybrid composite electrodes by the electrophoretic deposition (EPD) method for supercapacitor application," RSC Advances, vol. 6, no. 103, pp. 101592-101601, 2016.

[136] A. Gigot, M. Fontana, M. Serrapede et al., "Mixed 1T-2H phase $\mathrm{MoS}_{2} /$ reduced graphene oxide as active electrode for enhanced supercapacitive performance," ACS Applied Materials \& Interfaces, vol. 8, no. 48, pp. 32842-32852, 2016. 


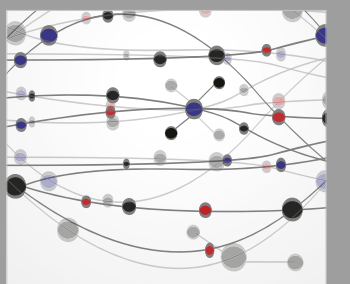

The Scientific World Journal
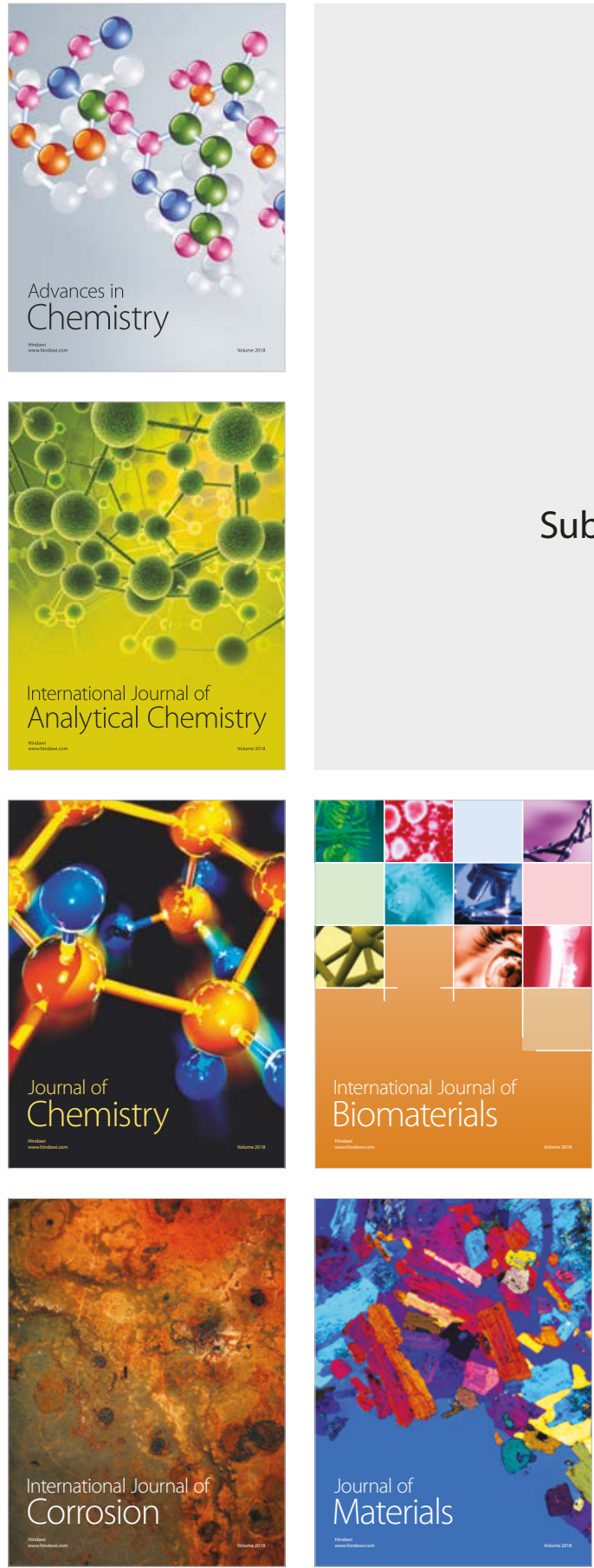

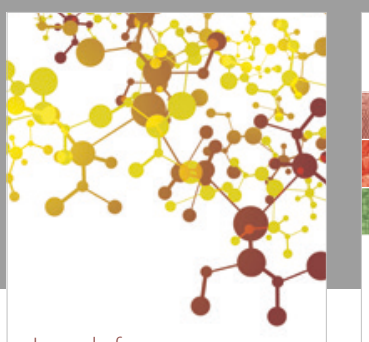

Journal of

Applied Chemistry
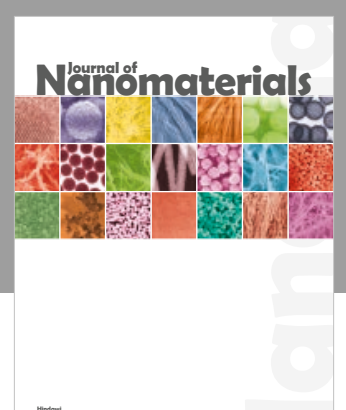

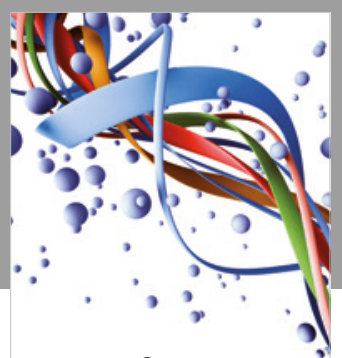

Scientifica

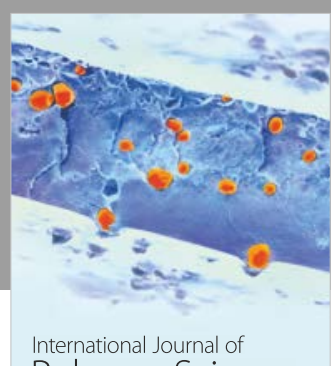

Polymer Science

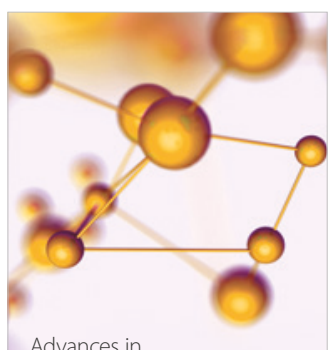

Physical Chemistry
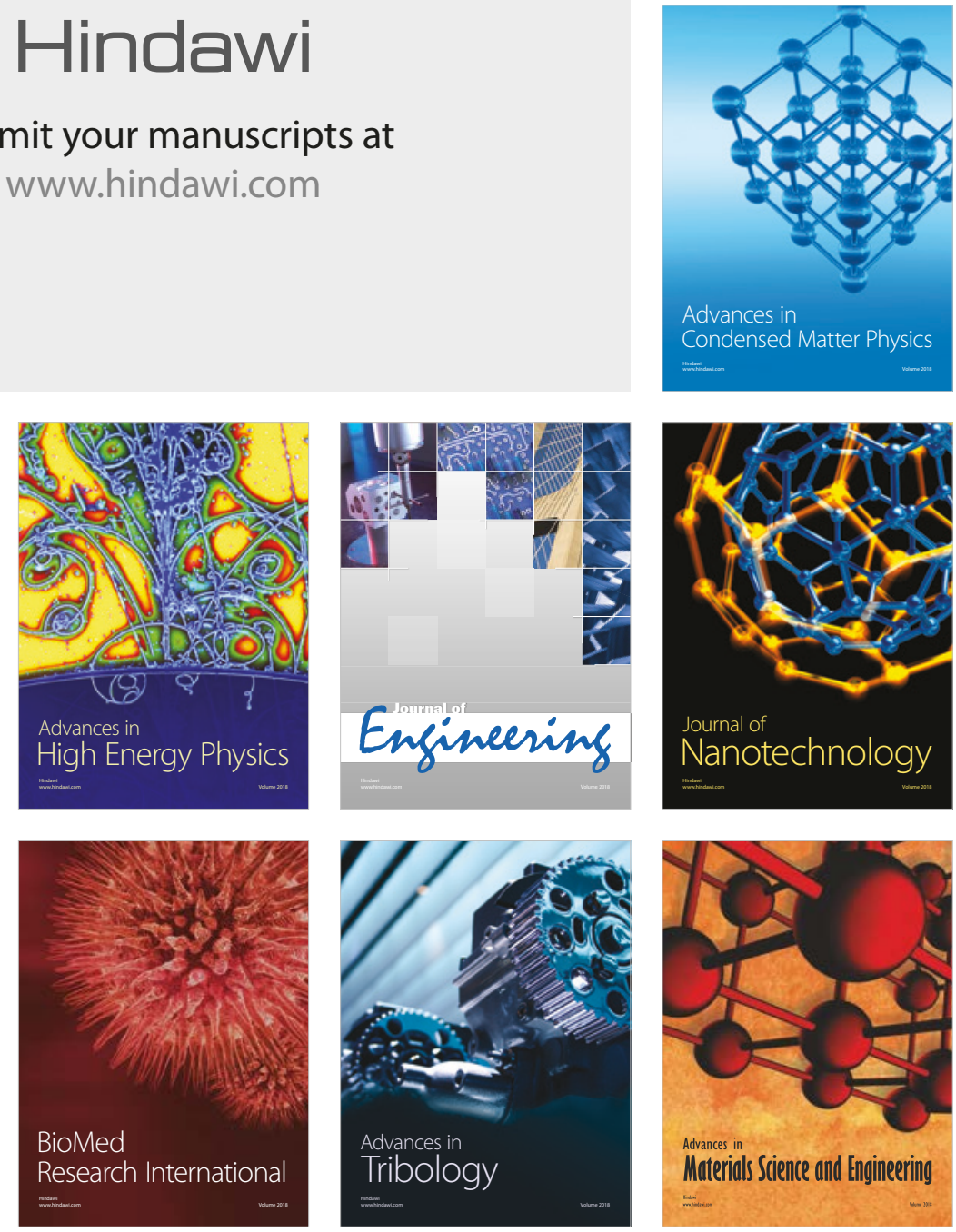